\title{
An Experimental and Modeling Study of Propene Oxidation. Part 2: Ignition Delay Time and Flame Speed Measurements.
}

Sinéad M. Burke ${ }^{\mathrm{a}}$, Ultan Burke ${ }^{\mathrm{a}}$, Reuben Mc Donagh ${ }^{\mathrm{a}}$, Olivier Mathieu ${ }^{\mathrm{b}}$, Irmis Osorio ${ }^{\mathrm{b}}$, Charles Keesee $^{b}$, Anibal Morones ${ }^{b}$, Eric L. Petersen ${ }^{b}$, Weijing Wang ${ }^{c}$, Trent A.

DeVerter $^{\mathrm{c}}$, Matthew A. Oehlschlaeger ${ }^{\mathrm{c}}$, Brandie Rhodes ${ }^{\mathrm{d}}$, Ronald K. Hanson ${ }^{\mathrm{d}}$, David Davidson $^{\mathrm{d}}$, Bryan W. Weber ${ }^{\mathrm{e}}$, Chih-Jen Sung ${ }^{\mathrm{e}}$, Jeffrey Santner ${ }^{\mathrm{f}}$, Yiguang Ju ${ }^{\mathrm{f}}$, Francis M. Haas $^{\mathrm{f}}$, Frederick L. Dryer ${ }^{\mathrm{f}}$, Evgeniy N. Volkov ${ }^{\mathrm{g}}$, Elna J.K. Nilsson ${ }^{\mathrm{h}}$, Alexander A. Konnov $^{\mathrm{h}}$, Majed Alrefae ${ }^{\mathrm{i}}$, Fethi Khaled ${ }^{\mathrm{i}}$, Aamir Farooq ${ }^{\mathrm{i}}$, Patricia Dirrenberger ${ }^{\mathrm{j}}$, PierreAlexandre Glaude ${ }^{j}$, Frédérique Battin-Leclerc ${ }^{\mathrm{j}}$, Henry J. Curran ${ }^{\mathrm{a}}$

${ }^{a}$ Combustion Chemistry Centre, National University of Ireland, Galway, Ireland. ${ }^{b}$ Department of Mechanical Engineering, Texas A\&M University, College Station, TX, United States. ${ }^{c}$ Department of Mechanical, Aerospace, and Nuclear Engineering Rensselaer Polytechnic Institute, Troy, NY, United States. ${ }^{d}$ Department of Mechanical Engineering, Stanford University, CA, United States. ${ }^{e}$ Department of Mechanical Engineering, University of Connecticut, CT, United States. ${ }^{f}$ Department of Mechanical and Aerospace Engineering, Princeton University, Princeton, NJ, United States. ${ }^{g}$ Technical University of Eindhoven, Eindhoven, the Netherlands. ${ }^{h}$ Division of Combustion Physics, Lund University, Lund, Sweden. ${ }^{i}$ Clean Combustion Research Center, King Abdullah University of Science and Technology, Thuwal, Kingdom of Saudi Arabia. ${ }^{j}$ Laboratoire Réactions et Génie des Procédés, CNRS-Université de Lorraine, Nancy, France.

\section{Abstract}

Experimental data obtained in this study (Part II) complement the speciation data presented in Part I, but also offer a basis for extensive facility cross-comparisons for both experimental ignition delay time (IDT) and laminar flame speed (LFS) observables.

To improve understanding of the ignition characteristics of propene, a series IDT experiments were performed in six different shock tubes and two rapid compression machines (RCMs) under conditions not previously studied. This study is the first of its kind to directly compare ignition in several different shock tubes over a wide range of conditions. For common nominal reaction conditions among these facilities, cross-comparison of shock tube IDTs suggests $20-30 \%$ reproducibility $(2 \sigma)$ for the IDT observable. The combination of shock tube and RCM data greatly expands the data available for validation of propene oxidation models to higher pressures (2-40 atm) and lower temperatures (750-1750 K).

Propene flames were studied at pressures from 1-20 atm and unburned gas temperatures of 295-398 K for a range of equivalence ratios and dilutions in different facilities. The present propene-air LFS results at 1 atm were also compared to LFS measurements from the literature. With respect to initial reaction conditions, the present experimental LFS cross-comparison is not as comprehensive as the IDT comparison; however, it still suggests reproducibility limits for the LFS observable. For the LFS results, there was agreement between certain data sets and for certain equivalence ratios (mostly in the lean region), but the remaining discrepancies highlight the need to reduce uncertainties in laminar flame speed experiments amongst different groups and different methods. Moreover, this is the first study to investigate the burning rate characteristics of propene at elevated pressures ( $>5 \mathrm{~atm}$ ).

IDT and LFS measurements are compared to predictions of the chemical kinetic mechanism presented in Part I and good agreement is observed.

Keywords:

Propene oxidation, shock tube, rapid compression machine, chemical kinetics, ignition, flame speed 


\section{Introduction}

As highlighted in Part I [1] of this study, propene is an important intermediate species in the combustion of larger hydrocarbons. In that paper speciation measurements were made in jet-stirred and flow reactors during propene oxidation and were presented along with a new detailed kinetic mechanism to describe propene oxidation. Here we present an investigation of the ignition and flame speed characteristics of propene across a wide range of conditions. Existing data in the literature are limited to relatively high-temperatures and low-pressures. The aim of this study is to expand the available experimental data for propene oxidation to lower temperatures and higher pressures. Table 1 is a compilation of ignition and flame speed measurements for propene reported in the literature compared with the present measurements.

Presented herein are the results of an unprecedented, comprehensive propene oxidation study conducted by several different groups using a wide assortment of experimental facilities and techniques, with the focus being on ignition delay times and laminar flame speeds. First is a section detailing the different facilities, starting with the shock tubes and followed by the rapid compression machine and flame speed facilities. A brief summary of the chemical kinetic mechanism is then given, including the assumptions and routines used to model the various experiments. A results section forms the bulk of the second half of this paper; it provides comparisons and analyses both between model and experiment as well as between experiments from different groups at overlapping conditions.

Table 1: Ignition delay time and flame speed data for propene.

\begin{tabular}{|c|c|c|c|c|c|}
\hline Reactor Type & $T / \mathrm{K}$ & $p /$ atm & $\varphi$ & Dilution & Ref. \\
\hline \multicolumn{6}{|c|}{ Parameter range for propene oxidation evident in the literature } \\
\hline \multicolumn{6}{|c|}{ Ignition Delay Time } \\
\hline Shock tube & $1274-1870$ & $2.19-7.04$ & $0.5-2.0$ & $84-97 \%$ & {$[2]$} \\
\hline Shock tube & $1200-1800$ & $\approx 2.65$ & - & $>95 \%$ & {$[3]$} \\
\hline Shock tube & $1270-1820$ & $0.95-4.7$ & $0.5-2.0$ & $>90 \%$ & [4] \\
\hline \multicolumn{6}{|c|}{ Flame Speed } \\
\hline Counterflow & 298 & 1 & $0.5-2.0$ & in 'air' & {$[5]$} \\
\hline Spherical flame & 298 & $1-5$ & $0.5-2.0$ & in 'air' & [6] \\
\hline Spherical flame & 293 and 425 & $0.5-3.5$ & $0.8-1.6$ & in 'air' & [7] \\
\hline \multicolumn{6}{|c|}{ Parameter range for propene oxidation obtained in this study } \\
\hline \multicolumn{6}{|c|}{ Ignition Delay } \\
\hline Shock tube & $1100-1750$ & $2-40$ & $0.5-2.0$ & $\approx 72-96 \%$ & \\
\hline $\mathrm{RCM}$ & $750-1100$ & $10-40$ & $0.5-2.0$ & $\approx 75-95 \%$ & \\
\hline \multicolumn{6}{|c|}{ Flame Speed } \\
\hline Heat flux method & 298-398 & 1 & $0.5-2.0$ & $\approx 70-80 \%$ & \\
\hline Spherical flame & $295-298$ & $1-20$ & $0.8-1.6$ & in 'air' $-\approx 80 \%$ & \\
\hline
\end{tabular}


Several studies have investigated propene pyrolysis and oxidation at high temperatures. Burcat and Radhakrishan [2] measured ignition delay times of 31-932 $\mu \mathrm{s}$ in the temperature range of 1274-1840 K and over a post-shock pressure range of 2.19-7.04 atm for propene/oxygen mixtures containing 84.0-96.7\% argon diluent. Qin et al. [4] measured shock tube ignition delay times in the temperature range of 1270 to $1820 \mathrm{~K}$ over a post-shock pressure range of $0.95-4.7$ atm with measured times of $10-1535 \mu$ s for propene $/ \mathrm{O}_{2} / \operatorname{argon}$ mixtures containing greater than $90 \%$ argon diluent. The measurements made in the Qin et al. study were observed to be shorter than those from the Burcat and Radhakrishan study under similar conditions; however, Qin et al. did not identify possible sources of the disagreement.

Hidaka et al. [3] investigated the thermal decomposition of propene behind reflected shock waves over a temperature range of 1200-1800 K, measuring the product distribution using infrared laser absorption spectroscopy and gas chromatography. The authors reported species profiles for $\mathrm{C}_{3} \mathrm{H}_{6}, \mathrm{C}_{2} \mathrm{H}_{2}, \mathrm{C}_{4} \mathrm{H}_{6}, \mathrm{C}_{3} \mathrm{H}_{4}$, and $\mathrm{C}_{6} \mathrm{H}_{6}$.

Law and co-workers $[5,6]$ reported laminar flame speed measurements for propene in two studies. Davis et al. [5] reported laminar flame speeds for propene/air mixtures at room temperature and atmospheric pressure carried out using the counterflow twin flame configuration. Jomaas et al. [6] investigated the laminar flame speed of $\mathrm{C}_{2}-\mathrm{C}_{3}$ hydrocarbons, including propene, from a spherical flame in a constant-pressure chamber at pressures of 1, 2 and $5 \mathrm{~atm}$. The laminar flame speed reported by Jomaas et al. at $\varphi=1.0$ is $\approx 3 \mathrm{~cm} \mathrm{~s}^{-1}$ slower than that reported by Davis et al. Saaed and Stone [7] studied burning velocities of propene-air mixtures at various temperatures $(293$ and $425 \mathrm{~K})$ and pressures $(0.5,1.0,2.0$ and 3.5 bar) in a constant-volume spherical vessel.

\section{Experimental Methods}

Ignition delay time measurements for propene were obtained in six different shock tube facilities; at NUI Galway (NUIG ST), Texas A\&M University (TAMU), Rensselaer Polytechnic Institute (RPI), Stanford University (SULP and SUHP), and King Abdullah University of Science and Technology (KAUST). Ignition delay time measurements were also obtained in two Rapid Compression Machines (RCMs) located at NUI Galway (NUIG RCM) and the University of Connecticut (UConn). Table 2 provides details of the important features of each facility.

Figure 1 shows a comparison of the conditions examined in this study and the previously published shock tube ignition delay times for propene oxidation. The present study covers a broader range of conditions particularly at higher pressures and lower temperatures than measurements previously found in the literature as shown in Table 1. Tabulated experimental data are included in the Supplementary Material.

An important feature of the present study is the direct comparison of ignition delay time measurements carried out at common experimental conditions in different shock tubes and rapid compression machines located at the co-author's respective institutions. Unambiguous comparisons of independent combustion kinetic target measurements, such as ignition delay time, are important because they provide cross-validation of facilities and experimental methods that have been used by the collaborator's research groups in numerous prior studies. Measurements made at common conditions in different facilities also provide a comparison of the collective scatter in the data from multiple facilities relative to the estimated uncertainty limits reported for each experiment, providing another assessment of the uncertainty estimates for kinetic targets, in this case ignition delay time. 


\begin{tabular}{|c|c|c|c|c|c|c|c|}
\hline Facility & $\begin{array}{l}\text { Driver } \\
\text { Length } \\
\text { (m) } \\
\end{array}$ & $\begin{array}{l}\text { Driven } \\
\text { Length } \\
\text { (m) } \\
\end{array}$ & $\begin{array}{l}\text { Internal } \\
\text { Diameter } \\
(\mathrm{cm}) \\
\end{array}$ & $\begin{array}{l}\text { Pressure range } \\
\quad \text { (atm) }\end{array}$ & $\begin{array}{l}\text { Test time } \\
\qquad(\mu s)\end{array}$ & Definition of $\tau$ & $\begin{array}{c}\text { Typical } \\
d p / d t(/ \mathrm{ms})\end{array}$ \\
\hline NUIG & 3.0 & 5.73 & 6.35 & $10-50$ & $50-2000$ & $\begin{array}{c}\text { From Reflection } \\
\text { to } \mathrm{dp} / \mathrm{dt} \text { at } \\
\text { ignition }\end{array}$ & $3-10 \%$ \\
\hline TAMU & 2.5 & 4.72 & 15.2 & $1-100$ & $50-2000$ & $\begin{array}{c}\text { Steepest } \\
\text { inflection of } \mathrm{P}, \\
\mathrm{OH}^{*} \text {, or } \mathrm{CH}^{*}\end{array}$ & $1-2 \%$ \\
\hline RPI & 2.59 & 4.11 & 5.7 & $5-100$ & 30-10000 & $\begin{array}{c}\text { From Reflection } \\
\text { to } \mathrm{dOH}^{*} / \mathrm{dt} \text { at } \\
\text { ignition }\end{array}$ & $3 \%$ \\
\hline SULP & 3.35 & 8.54 & $\begin{array}{c}14.13 \\
\left(2^{\text {nd }} \text { ST: } 15.34\right. \\
)\end{array}$ & $\begin{array}{c}0.1-20 \\
\left(2^{\text {nd }} \text { ST: } 0.1-50\right)\end{array}$ & $\begin{array}{l}\text { 1000-3000; } \\
\text { (tailoring } \\
\text { and } \\
\text { modified } \\
\text { driver } \\
\text { section } \\
\text { extends this } \\
\text { to } 25+\mathrm{ms} \text { ) } \\
\end{array}$ & $\begin{array}{l}\text { Based on } \mathrm{OH}^{*} \\
\text { emission or } \\
\text { pressure rise } \\
\text { extrapolated to } \\
\text { baseline }\end{array}$ & $\begin{array}{c}0.5-3 \% \text { (with } \\
\text { driver insert } \\
\sim 0 \% \text { ) }\end{array}$ \\
\hline SUHP & 3.0 & 5.0 & $\begin{array}{l}7.62 \text { driver / } \\
5.0 \text { driven }\end{array}$ & $1-1000$ & $\begin{array}{c}1000-8000 \\
\text { tailoring and } \\
\text { modified } \\
\text { driver } \\
\text { section } \\
\text { extends this } \\
\text { to } 20+\mathrm{ms}\end{array}$ & $\begin{array}{l}\text { Based on } \mathrm{OH}^{*} \\
\text { emission or } \\
\text { pressure rise } \\
\text { extrapolated to } \\
\text { baseline }\end{array}$ & $\begin{array}{c}2-7 \% \\
\text { (with driver } \\
\text { insert } \sim 0 \% \text { ) }\end{array}$ \\
\hline KAUST & 6.6 & 6.6 & 10 & $10-60$ & $50-20000$ & $\begin{array}{l}\text { From reflection to } \\
\text { sidewall/endwall } \\
\text { OH* peak }^{*} \text { emission }\end{array}$ & $3-4 \%$ \\
\hline
\end{tabular}

Table 2: Comparison of shock tube facilities used in this study.

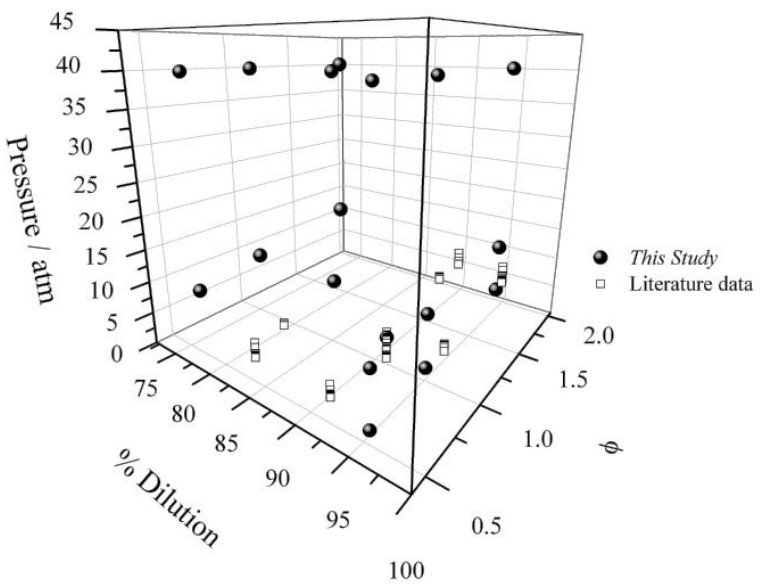

Figure 1: Comparison of condition space examined in this study to that of literature propene IDT data $[2,4]$. 
Similarly, laminar flame speed measurements are compared from five different experimental installations, Princeton University (PU) and Texas A\&M University (TAMU) utilized the spherical flame method. While Vrije Universiteit Brussel (VUB), Lund University (Lund) and Université de Lorraine (LRPG) used the heat-flux method.

\subsection{NUI Galway high-pressure shock tube}

Ignition delay time measurements were carried out in the high-pressure shock tube at NUI Galway ( $6.35 \mathrm{~cm}$ inner diameter) described in the recent study by Nakamura et al. [8]. The ignition delay time was defined as the interval between the rise in pressure due to the arrival of the reflected shock wave at the sidewall pressure transducer nearest the endwall and the maximum rate of rise of the pressure signal, as shown in Fig. 2. Post-shock conditions were determined using the normal shock relations as employed by GasEq [9] utilizing measurements of incident shock velocity, initial temperature and pressure, and the thermodynamic properties of the shock-heated propene/oxidizer mixtures [10].

Pre-ignition (as discussed by Shen et al. [11] and Petersen [12]) has been seen to affect fuel/air measurements in some systems, in particular at high pressures. Pre-ignition is due to non-ideal gas dynamic and shock effects. Where appreciable pre-ignition was observed (> $5 \% / \mathrm{ms}$ ), the ignition delay time measurements were not included for mechanism validation.

Measurements were made for propene/air mixtures at $\varphi=0.5$ and 1.0 at pressures of approximately 10 and 40 atm; and over a temperature range of approximately 1000 to $1400 \mathrm{~K}$. Air was defined as $\mathrm{O}_{2}$ and $\mathrm{N}_{2}$ in a ratio of 1 to 3.76. Additional measurements for dilute (argon $>95 \%) \mathrm{C}_{3} \mathrm{H}_{6} / \mathrm{O}_{2}$ mixtures at 40 atm over a temperature range of 1200 to $1500 \mathrm{~K}$ were also performed. The overall uncertainty for each individual ignition delay time is estimated at $20 \%$. Uncertainties in pressure, temperature, mixture composition, and those associated with the determination of the ignition delay time from the measured traces all contribute to the overall uncertainty.

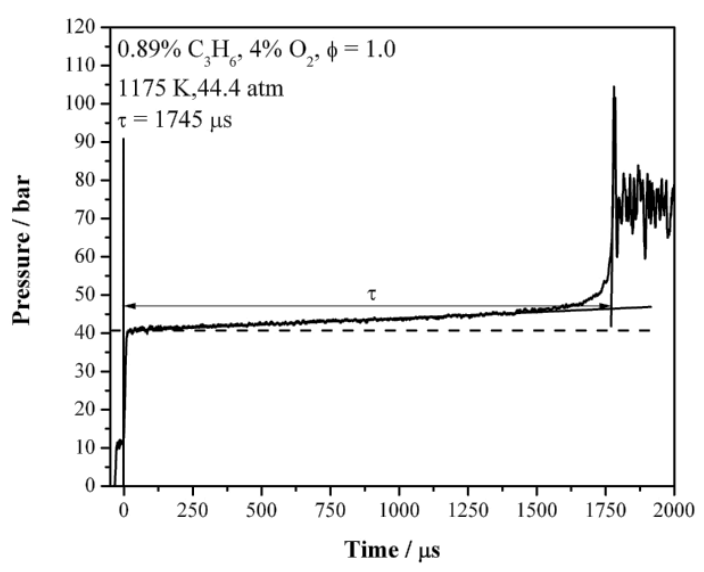

Figure 2: Sample pressure trace from NUI Galway shock tube, $d p / d t=1.23 \% / \mathrm{ms}$.

\subsection{Texas A\&M University shock tube}

The single diaphragm, stainless steel, shock tube used at Texas A\&M University was 7.18$\mathrm{m}$ long. The driven section had a 15.24-cm i.d., and was 4.72-m long, the driver section had an inner diameter of $7.62 \mathrm{~cm}$. Helium was used as the driver gas during this study. A schematic of the shock-tube setup can be found in Aul et al. [13]. Polycarbonate diaphragms were used to separate the two sections; 0.25 -mm thickness for the 2-atm experiments and $1.75 \mathrm{~mm}(1.0+$ $3 \times 0.25 \mathrm{~mm})$ thickness for the 10 -atm experiments. A cross-shaped cutter was employed to 
break the diaphragm and prevent diaphragm fragments from tearing off. The driven section was evacuated to $2 \times 10^{-5}$ Torr or better using a roughing pump and a Varian 551 Turbomolecular pump prior to every run. The pumping time between experiments was minimized using a pneumatically driven poppet valve matching the inside diameter of the driven section and allowing for a passage of $7.62 \mathrm{~cm}$ diameter between the vacuum section and the driven tube.

The incident-wave velocities were measured using Five PCB P113A piezoelectric pressure transducers along with four Fluke PM-6666 timer/counter boxes. The transducers were equally spaced alongside the driven section and are mounted flush with the inner surface of the shocktube walls. Test pressure was monitored by one PCB 134A located at the endwall and one Kistler 603 B1 located at the sidewall, in the same plane as the sapphire observation windows (located $16 \mathrm{~mm}$ from the endwall). Non-ideal boundary layer effects leading to a change in pressure $(d p / d t)$ behind the reflected shock wave were determined to be $2 \% / \mathrm{ms}$ or less for all experiments.

Ignition delay time measurements were made for propene mixtures diluted in $\mathrm{Ar}$ at compressed pressures of approximately 2 and $10 \mathrm{~atm}$. Both pressure and $\mathrm{OH}^{\star}$ (sidewall location) diagnostics were recorded during this study. The equivalence ratio ranged from 0.5 to 2, and the compositions of the mixtures investigated are presented in Table 3 . For the mixtures with dilution levels lower than $90 \%$ of Ar by volume, the ignition delay time was defined as the time between the arrival of the incident shock wave at the endwall and the time at which the endwall pressure signal exhibits a sharp increase due to the mixture reactivity, Fig. 3(a). For the mixtures with a dilution level larger than $90 \%$, the ignition delay time was defined as the time between the arrival of the shock wave at the sidewall and the intersection of lines drawn along the steepest rate-of-change of $\mathrm{OH}^{\star}$ de-excitation and a horizontal line which defines the zero-concentration level, Fig. 3(b).

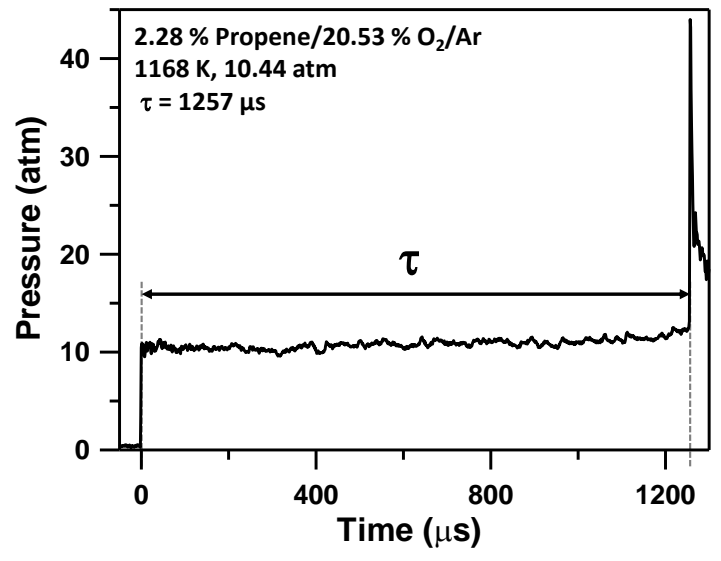

(a) Low dilution mixture (endwall)

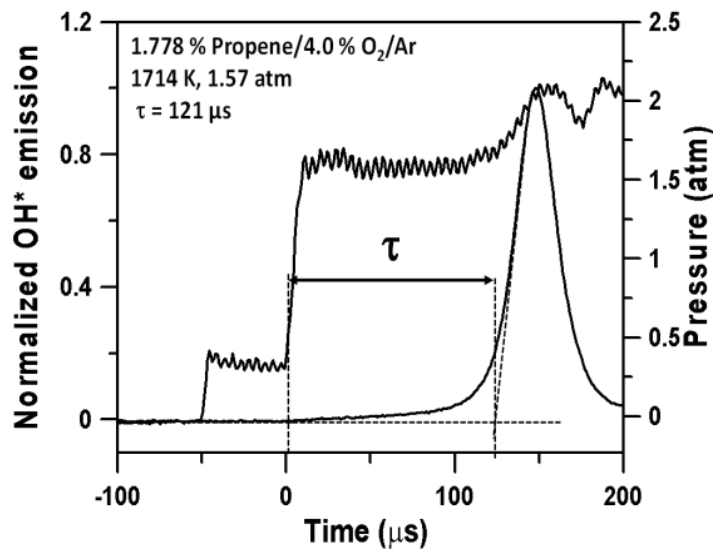

(b) High dilution mixture (sidewall)

Figure 3: Sample pressure traces from TAMU shock tube for two different dilution levels.

Table 3: Experimental conditions for different Shock Tube and RCM facilities.

\begin{tabular}{|c|c|c|c|c|c|c|}
\hline \multicolumn{7}{|c|}{ NUI Galway } \\
\hline \hline No. & Propene \% & $\mathrm{O}_{2} \%$ & Diluent $\%$ & $\varphi$ & $p_{5}$ atm & Facility \\
\hline 1 & 2.25 & 20.53 & 77.22 & 0.5 & 10 & ST \\
3 & 4.46 & 20.07 & 75.47 & 1.0 & 10 & ST \\
3 & 0.89 & 4.00 & 95.11 & 1.0 & 40 & ST
\end{tabular}




\begin{tabular}{|c|c|c|c|c|c|c|}
\hline 4 & 2.25 & 20.53 & 77.22 & 0.5 & 10 & $\mathrm{RCM}$ \\
\hline 5 & 0.45 & 4.00 & 95.55 & 0.5 & 10 & RCM \\
\hline 6 & 4.46 & 20.07 & 75.47 & 1.0 & 10 & $\mathrm{RCM}$ \\
\hline 7 & 2.67 & 12.00 & 85.33 & 1.0 & 10 & $\mathrm{RCM}$ \\
\hline 8 & 0.89 & 4.00 & 95.11 & 1.0 & 10 & RCM \\
\hline 9 & 2.25 & 20.53 & 77.22 & 0.5 & 40 & RCM \\
\hline 10 & 0.45 & 4.00 & 95.55 & 0.5 & 40 & $\mathrm{RCM}$ \\
\hline 11 & 4.46 & 20.07 & 75.47 & 1.0 & 40 & $\mathrm{RCM}$ \\
\hline 12 & 2.67 & 12.00 & 85.33 & 1.0 & 40 & $\mathrm{RCM}$ \\
\hline 13 & 0.89 & 4.00 & 95.11 & 1.0 & 40 & $\mathrm{RCM}$ \\
\hline \multicolumn{7}{|c|}{$T A M U$} \\
\hline 14 & 2.25 & 20.53 & 77.22 & 0.5 & 2 & $\begin{array}{l}\mathrm{ST} \\
\end{array}$ \\
\hline 15 & 2.67 & 12.00 & 85.33 & 1.0 & 2 & ST \\
\hline 16 & 0.89 & 4.00 & 95.11 & 1.0 & 2 & ST \\
\hline 17 & 1.78 & 4.00 & 94.22 & 2.0 & 2 & ST \\
\hline 18 & 2.25 & 20.53 & 77.22 & 0.5 & 10 & $\mathrm{ST}$ \\
\hline 19 & 4.46 & 20.07 & 75.47 & 1.0 & 10 & ST \\
\hline 20 & 2.67 & 12.00 & 85.33 & 1.0 & 10 & ST \\
\hline 21 & 0.89 & 4.00 & 95.11 & 1.0 & 10 & ST \\
\hline 22 & 1.78 & 4.00 & 94.22 & 2.0 & 10 & ST \\
\hline \multicolumn{7}{|c|}{$R P I$} \\
\hline 23 & 2.25 & 20.53 & 77.22 & 0.5 & 10 & $\overline{\mathrm{ST}}$ \\
\hline 24 & 4.46 & 20.07 & 75.47 & 1.0 & 10 & ST \\
\hline 25 & 2.67 & 12.00 & 85.33 & 1.0 & 10 & ST \\
\hline 26 & 8.54 & 19.21 & 72.25 & 2.0 & 10 & ST \\
\hline 27 & 2.25 & 20.53 & 77.22 & 0.5 & 40 & ST \\
\hline 28 & 4.46 & 20.07 & 75.47 & 1.0 & 40 & $\mathrm{ST}$ \\
\hline 29 & 2.67 & 12.00 & 85.33 & 1.0 & 40 & $\mathrm{ST}$ \\
\hline 30 & 8.54 & 19.21 & 72.25 & 2.0 & 40 & ST \\
\hline
\end{tabular}

\begin{tabular}{|c|c|c|c|c|c|c|}
\hline \multicolumn{7}{|c|}{ Stanford } \\
\hline 31 & 0.89 & 4.00 & 95.11 & 1.0 & 2 & ST \\
\hline 32 & 0.45 & 4.00 & 95.55 & 0.5 & 2 & ST \\
\hline 33 & 1.78 & 4.00 & 94.22 & 2.0 & 2 & ST \\
\hline 34 & 0.89 & 4.00 & 95.11 & 1.0 & 4.5 & ST \\
\hline 35 & 1.67 & 7.20 & 91.13 & 1.0 & 4.5 & $\mathrm{ST}$ \\
\hline 36 & 0.89 & 4.00 & 95.11 & 1.0 & 40 & ST \\
\hline 37 & 1.78 & 4.00 & 94.22 & 2.0 & 40 & $\mathrm{ST}$ \\
\hline \multicolumn{7}{|c|}{ UCONN } \\
\hline 38 & 4.46 & 20.07 & "75.47 & 1.0 & 10 & $\overline{\mathrm{RCM}}$ \\
\hline 39 & 2.67 & 12.00 & 85.33 & 1.0 & 10 & RCM \\
\hline 40 & 8.54 & 19.21 & 72.25 & 2.0 & 10 & RCM \\
\hline
\end{tabular}




\begin{tabular}{|l|l|l|l|l|l|l|}
41 & 0.89 & 4.00 & 95.11 & 1.0 & 40 & RCM \\
42 & 2.67 & 12.00 & 85.33 & 1.0 & 40 & RCM \\
43 & 1.78 & 4.00 & 94.22 & 2.0 & 10 & RCM \\
44 & 1.78 & 4.00 & 94.22 & 2.0 & 40 & RCM \\
\hline \hline KAUST \\
\begin{tabular}{|l|l|l|l|l|l|l|}
\hline 45 & 2.25 & 20.53 & 77.22 & 0.5 & 40 & ST \\
46 & 4.46 & 20.07 & 75.47 & 1.0 & 40 & ST \\
47 & 8.54 & 19.21 & 72.25 & 2.0 & 40 & ST \\
\hline
\end{tabular}
\end{tabular}

The measured pressures, temperatures, and ignition delay times for each experiment from each facility are included in the Supplementary Material.

\subsection{Rensselaer Polytechnic Institute shock tube}

Ignition delay time measurements were carried out in the high-pressure shock tube at Rensselaer $(5.7 \mathrm{~cm}$ inner diameter) previously described by Shen and Oehlschlaeger [14]. In the present study the shock tube was not heated and ignition delay time measurements were made in stationary reflected shock-heated gases using the side wall pressure, measured $2 \mathrm{~cm}$ from the driven section endwall, and electronically-excited hydroxyl radical chemiluminescence $\left(\mathrm{OH}^{\star}\right)$ measured at the endwall [14]. An example ignition delay time measurement is shown in Fig. 4. Post-shock conditions were determined using the normal shock relations utilizing measurements of incident shock velocity, initial temperature and pressure, and the thermodynamic properties of the shock-heated propene/oxidizer mixtures [10]. The facility shows typical viscosity induced attenuation rates of 1 to $2 \%$ in incident shock velocity per meter and pressure gradients of $d p / d t=2$ to $3 \% / \mathrm{ms}$ for the range of condition considered in this study.

Measurements were made for propene/air mixtures at $\varphi=0.5,1.0$, and 2.0; at pressures of approximately 10 and $40 \mathrm{~atm}$; and for a temperature range of approximately 1000 to $1400 \mathrm{~K}$. Air was defined as $99.995 \%$ pure $\mathrm{O}_{2}$ and $\mathrm{N}_{2}$ (from Noble Gas) at a ratio of 1 to 3.76; propene was from Aldrich at $99+\%$ purity. Ignition delay measurements were also made for dilute stoichiometric mixtures containing $2.667 \%$ propene, $12 \% \mathrm{O}_{2}$, and $85.33 \% \mathrm{Ar}$ (Ar from Noble Gas at $99.995 \%$ purity) at 10 and $40 \mathrm{~atm}$ and approximately 1160 to $1460 \mathrm{~K}$. An additional set of measurements was carried out at 10 atm for a dilute stoichiometric mixture containing $85.33 \% \mathrm{~N}_{2}$. No discernible difference in ignition delay for $\mathrm{Ar}$ and $\mathrm{N}_{2}$-diluted mixtures was observed.

The uncertainty in ignition delay time is estimated at $\pm 20 \%$ based on the uncertainty contributions from reflected shock conditions (temperature, pressure, and mixture fractions) and those associated with determining ignition delay from the measured signals. 


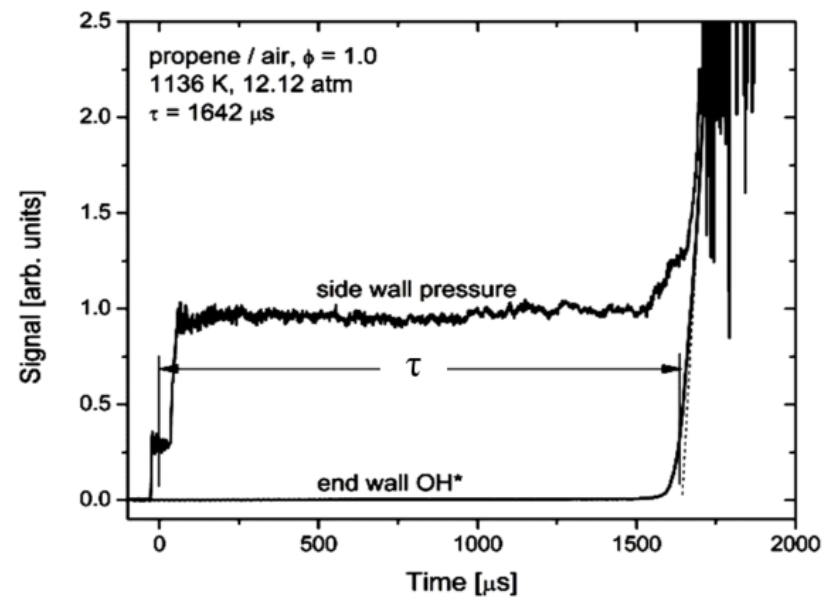

Figure 4: Sample pressure trace from RPI shock tube.

\subsection{Stanford University shock tube}

Ignition delay time measurements were obtained in two shock tubes located at Stanford University. The first facility was a high-purity, low-pressure shock tube used to IDTs for reflected shock pressures of $<5$ atm (SULP). A second high-pressure shock tube was used to obtain IDTs at $p_{5} \approx 40$ atm (SUHP).

\subsubsection{Low-pressure shock tube}

The Stanford stainless-steel low-pressure shock tube has an inner diameter of $14.1 \mathrm{~cm}$, and the driven section is 8.54- $\mathrm{m}$ in length. The driver section is $3.35-\mathrm{m}$ long and helium is used as the driver gas. The driver and driven section are separated by a polycarbonate diaphragm [14]. At a sidewall location $2 \mathrm{~cm}$ from the endwall, diagnostics were set up to measure pressure and $\mathrm{OH}^{\star}$ emission in the reflected shock region. Another $\mathrm{OH}^{\star}$ emission diagnostic was installed through the endwall. Figure 5 shows a schematic.

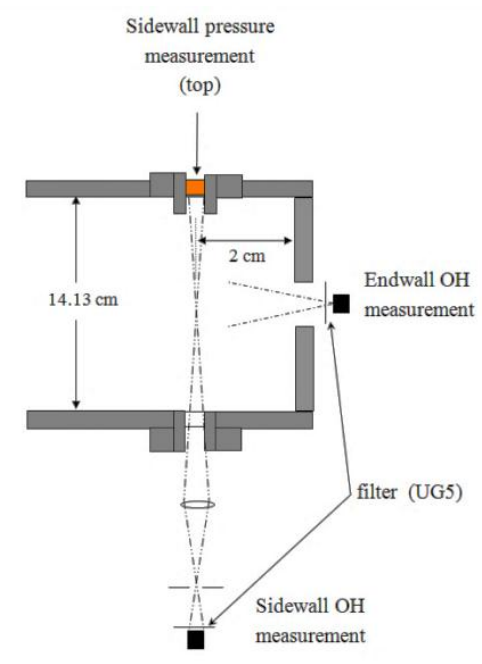

Figure 5: Schematic of the $\mathrm{OH}^{\star}$ emission diagnostic in Stanford University.

The incident shock speeds were determined from arrival-time measurements using 5 pressure transducers placed at approximately $30 \mathrm{~cm}$ intervals and four time-interval counters. The incident shock speed at the endwall was then determined by extrapolation, and this speed was used in the calculation of the initial reflected shock temperature and pressure using the onedimensional shock-jump relations and assuming vibrational equilibrium and frozen chemistry; 
this approach provided uncertainties in initial post-shock temperature and pressure of less than $\pm 1 \%$. At lower temperatures where longer test times are required, near-constant pressure profiles over the longer test times were achieved by using driver inserts. Further details on driver insert design can be found in Hong et al. [16].

Ignition delay time data were acquired at both the sidewall and endwall locations. In experiments with strong energy release at ignition, blast waves forming immediately adjacent to the endwall can move and perturb the normally stagnant test gas mixtures observed at the side wall location. In experiments with very short ignition delay times (e.g. sub 50-100 $\mu$ s) this perturbation can artificially shorten the observed ignition delay time. In these cases endwall data is preferred [17].

\subsubsection{High-pressure shock tube}

The high-pressure studies (40-50 atm) were performed in the heated high-pressure shock tube. For the high-pressure measurements ignition delay times were scaled using the pressure coefficient 0.77 according to the following equation:

$$
\tau_{\text {scaled }}=\left(\tau_{\text {non-scaled }}\right)\left(\frac{P[\mathrm{~atm}]}{40 \mathrm{~atm}}\right)^{0.77}
$$

The coefficient 0.77 was obtained through a regression utilizing the ignition delay times obtained experimentally at approximately 2,4 , and 45 atm.

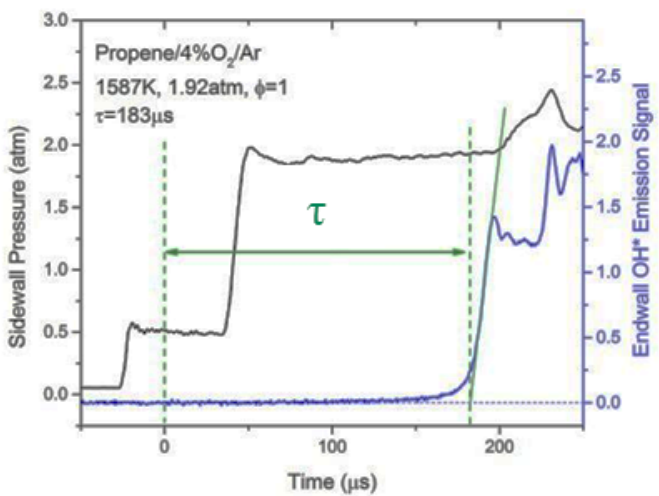

(a) Low-pressure shock tube, zero time is set to the arrival of the reflected shock at the endwall.

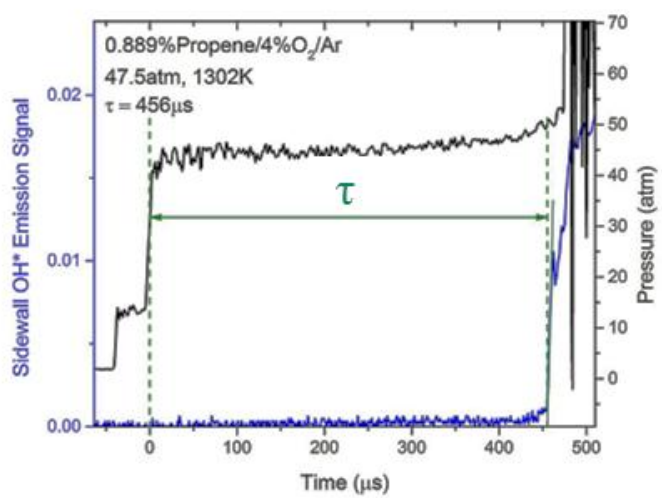

(b)High-pressure shock tube.

Figure 6: Sample traces from the low and high-pressure shock tubes at Stanford.

The driver section is 3-m long and has an internal diameter of $7.5 \mathrm{~cm}$. The stainless steel driven section has a length of 5-m and an internal diameter of $5 \mathrm{~cm}$. Incident shock waves were formed by bursting scribed aluminum diaphragms with high-pressure helium. Non-ideal pressure effects caused by boundary layer growth and incident shock wave attenuation were reduced through the implementation of driver inserts. Incident shock speeds were measured using five axially-spaced piezoelectric pressure transducers (PCB 113A) placed at approximately $30 \mathrm{~cm}$ intervals from the endwall of the driven section. The velocity of the incident shock at the end wall was determined by extrapolation, allowing calculation of the initial reflected shock temperature and pressure, by using one-dimensional shock-jump relations and assuming vibrational equilibrium and frozen chemistry, with uncertainties in initial post-shock temperature and pressure of less than $\pm 1 \%$. The driven section was evacuated to an ultimate pressure of less than $10^{-5}$ Torr, with a combined leak and outgassing 
rate of less than $10^{-4}$ Torr/min before each shock. Praxair research grade oxygen and argon and Sigma Aldrich propene $(99+\%)$ were used to prepare fuel mixtures. Test-gas mixtures were prepared manometrically and homogenized using a magnetically-driven stirring assembly inside the mixing tank for at least $30 \mathrm{~min}$ prior to the experiments. Ignition delay times were measured using both sidewall $\mathrm{OH}^{\star}$ emission and sidewall pressure.

\subsection{King Abdullah University of Science and Technology (KAUST) shock tube}

The high-pressure shock tube (HPST) at KAUST was used to measure the ignition delay times of propene in air at a nominal pressure of 40 bar. The HPST is constructed from stainless steel, where the inner surface is electro-polished to reduce boundary layers. The inner diameter of the HPST is $10 \mathrm{~cm}$; the driven section is $6.6 \mathrm{~m}$ long and the driver section length can be varied up to a maximum of $6.6 \mathrm{~m}$. The driven and the driver sections are separated by pre-scored aluminum diaphragms to achieve the required pressure behind the reflected shock wave. Before filling the test mixture, the tube is evacuated to pressures of less than $10^{-5}$ Torr using a turbo-molecular pump. The test mixture is prepared manometrically in a mixing vessel equipped with a magnetic stirrer.

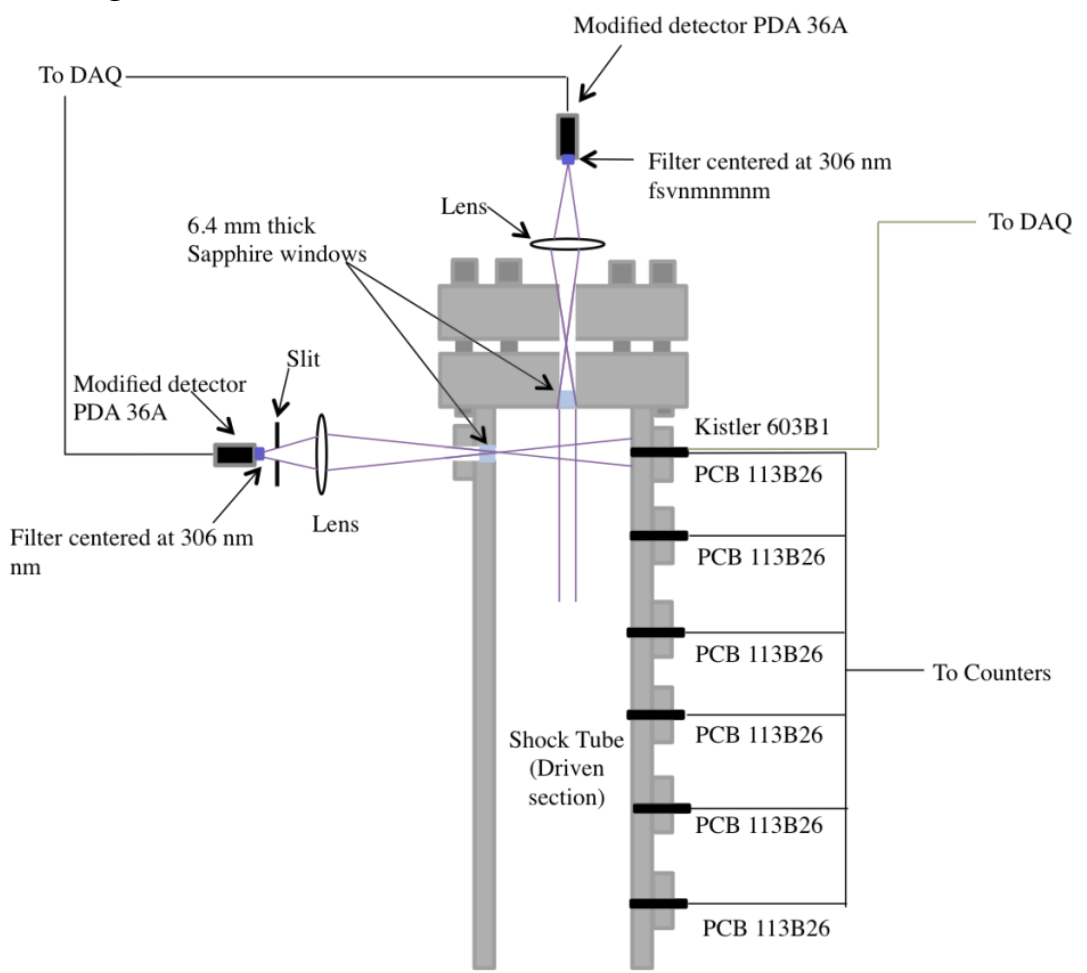

Figure 7: Optical configuration for ignition delay time measurements in the KAUST highpressure shock tube.

The shock velocity is measured using six PCB $113 \mathrm{~B} 26$ piezoelectric pressure transducers (PZTs) that are located axially along the last $2.8 \mathrm{~m}$ of the driven section. The signals from PZTs are used to trigger five ultrafast $(350 \mathrm{MHz})$ Agilent $53220 \mathrm{~A}$ frequency counters to determine the time interval between the shock passing two successive pressure transducers. The shock attenuation rates vary from 0.2 to $1.5 \%$ per meter in the incident shock velocity and reflected-shock pressure gradients $(d p / d t)$ of $\sim 3 \% / \mathrm{ms}$ were observed for the range of conditions considered herein. The shock jump relations and known thermodynamic parameters are then used to calculate the post-reflected shock conditions ( $p_{5}$ and $T_{5}$ ). The sidewall pressure is measured using a Kistler 603B1 PZT located at $1.0 \mathrm{~cm}$ from the endwall. $\mathrm{OH}^{\star}$ emissions were monitored through Sapphire windows at the endwall and the sidewall locations 
using Thorlabs PDA36A detectors and narrow band-pass optical filters. The experimental setup is shown in Fig. 7.

The ignition delay time is defined as the period of time from the arrival of the reflected shockwave to the onset of ignition. The pressure trace and the $\mathrm{OH}^{\star}$ emission, detected at the endwall and the sidewall, are used to determine the onset of ignition, as shown in Fig. 9. Ignition delay times measured using the sidewall pressure trace, sidewall emission, and endwall emission are all within $5 \%$. The uncertainty of the measured ignition delay times in this work is $\pm 15 \%$ due primarily to the uncertainty in the reflected shock temperature. The propene/air ignition delay times were measured for equivalence ratios of 0.5, 1.0 and 2.0, where the temperatures ranged from 1000 to $1350 \mathrm{~K}$ and the pressures were close to $40 \mathrm{bar}$.

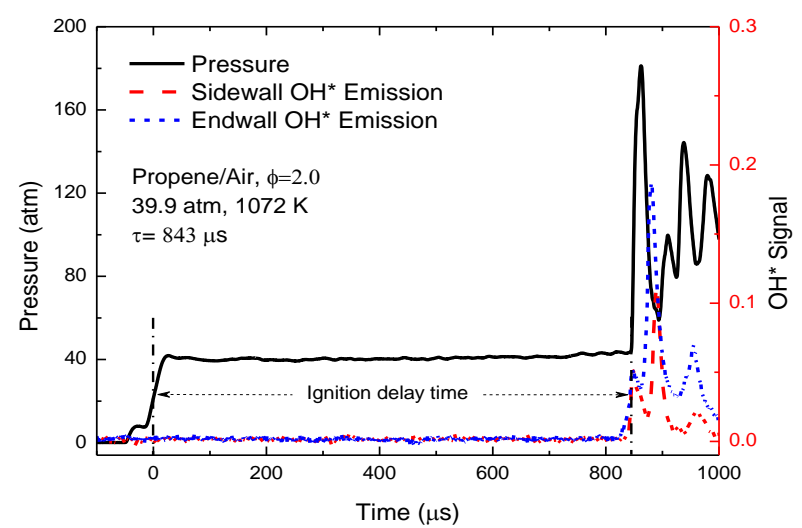

Figure 8: Sample pressure trace from KAUST shock tube.

\subsection{NUI Galway rapid compression machine}

The NUI Galway RCM has been described in detail by Darcy et al. [18]. Briefly, it is a duplicate of the original NUI Galway RCM [18] which is characteristically different from most other RCMs in that it has a twin-opposed piston configuration as described previously [18]. A typical pressure trace obtained from this facility is included Fig. 9(a). It outlines the ignition delay definition used in all experiments. The adiabatic compression/expansion program of GasEq [9] is used to calculate the compressed gas temperature and pressure. The ignition delay time, was defined as the time from the end of compression to the maximum rate of pressure rise. End of compression is defined as the first local maximum in pressure.

For both the NUI Galway high-pressure shock tube and RCM experiments, propene gas was obtained from Sigma Aldrich at $>99 \%$ purity. Helium, oxygen, nitrogen and argon gases were obtained from BOC at $>99.99 \%$ purity. All gases were used without further purification. Experiments are taken in triplicate and the compressed pressure and ignition delay time was found to be reproducible within $15 \%$.

\subsection{UConn rapid compression machine}

The University of Connecticut RCM has been described extensively elsewhere [20]. Briefly, it consists of a single-piston, pneumatically driven, hydraulically stopped arrangement. The pressure $\left(p_{\mathrm{C}}\right)$ and temperature $\left(T_{\mathrm{C}}\right)$ at the end of compression (EOC), can be independently varied by changing the volumetric compression ratio, the initial temperature, and the initial pressure. Using this procedure, $p_{\mathrm{C}}$ can be controlled to within \pm 0.1 bar on consecutive runs with the same initial conditions. The piston in the reaction chamber is machined with specially designed crevices to minimize the effect of the roll-up vortex and 
ensure homogeneous conditions in the reaction chamber. During and after compression, the pressure in the reaction chamber is monitored by a rapid-response dynamic pressure transducer; the initial pressure is measured by a static pressure transducer. The reactants are brought to the EOC conditions in approximately $30-50 \mathrm{~ms}$, depending on the volumetric compression ratio and the pneumatic driving pressure chosen. Fuel and oxidizer are premixed in large stainless steel mixing tanks to facilitate performing many experiments during one day. Two mixing tanks are used: one is used to hold a reactive mixture, and is approximately $17 \mathrm{~L}$ in volume; the other is approximately $16 \mathrm{~L}$ and used to hold a non-reactive mixture, whose utility will be discussed below. The reactants $\left(\mathrm{C}_{3} \mathrm{H}_{6} / \mathrm{O}_{2} / \mathrm{N}_{2} / \mathrm{Ar}\right)$ are filled at room temperature to the calculated partial pressure required to achieve the mole fractions outlined in Table 3. Note that the 10 atm data used diluent mixtures consisting of $50 \% \mathrm{~N}_{2} / 50 \%$ Ar; the 40 atm data used a diluent of pure $\mathrm{N}_{2}$. During filling of the mixing tanks, the pressure is monitored by a static pressure transducer. Subsequently, heaters are turned on and a magnetic stirrer is used to mix the reactants in the tank. The system is allowed to stabilize for approximately 1.5 hours at the specified initial temperature.

Figure 9(b) shows a representative pressure trace from these experiments at $p_{\mathrm{C}}=10 \mathrm{~atm}$, $T_{\mathrm{C}}=918 \mathrm{~K}$, and $\varphi=1.0 \mathrm{in}$ air. The definitions of the end of compression and the ignition delay are indicated on the figure. The end of compression time is defined as the first local maximum in pressure. The ignition delay is the time from the end of compression until the largest peak in the time derivative of the pressure. Each unique condition is repeated at least 5 times to ensure repeatability of the experiments. The experiment closest to the mean of the runs at a particular condition is chosen for analysis and presentation. The standard deviation of all of the runs at a condition is less than $10 \%$ of the mean in all cases. Furthermore, to ensure reproducibility, each new mixture preparation is checked against a previously run condition before new data is collected using that mixture.

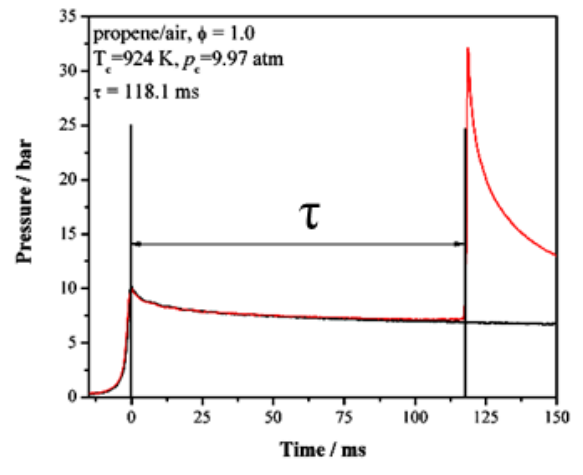

(a) NUI Galway

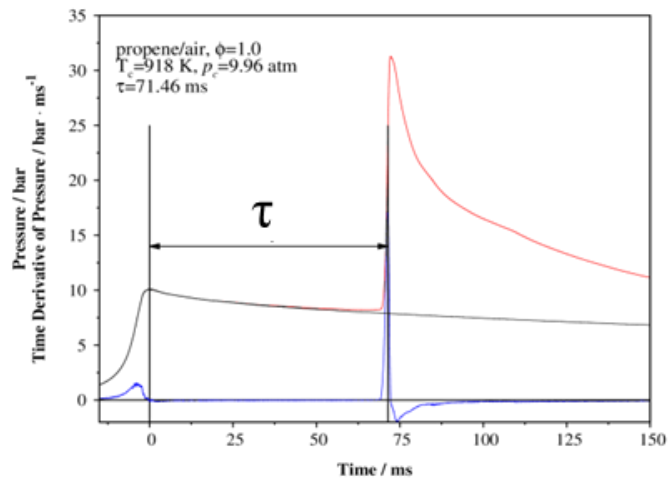

(b)UConn

Figure 9: Sample pressure traces from NUI Galway and UConn RCMs. — Nonreactive profile, $\_$reactive profile, _- time derivative of pressure.

\subsection{Shock tube simulation}

Shock tube simulations were performed as zero-dimensional calculations and begin at the onset of the reflected shock period. Constant volume, homogeneous, and adiabatic conditions were assumed behind the reflected shock wave, as all experiments were near this assumption especially when the minimal pressure increases reported are considered. The reflected shock pressure $\left(p_{5}\right)$ and temperature $\left(T_{5}\right)$ were used as the initial pressure and temperature, respectively. For ignition delay computations, the simulated ignition delay time is defined in order to be consistent with the particular diagnostic used in the experiment being simulated. 
As excited $\mathrm{CH}^{\star}$ and $\mathrm{OH}^{\star}$ are often used as a diagnostics for light emission, the mechanism presented in this study contains a sub-mechanism for both $\mathrm{CH}^{\star}$ and $\mathrm{OH}^{\star}$ which have been adopted from Hall and Petersen [21] and Kathrotia et al. [22] respectively.

\subsubsection{Brute-force sensitivity}

In order to highlight the most important reactions controlling ignition delay time 'brute force' sensitivity analyses were performed for a constant volume simulation. The analysis was carried out by individually increasing and decreasing each reaction rate expression as written in the mechanism by a factor of two and calculating the effect on the predicted ignition delay time. The sensitivity coefficient is defined as: $S=\frac{\ln \left(\tau_{+} / \tau_{-}\right)}{\ln \left(k_{+} / k_{-}\right)}=\frac{\ln \left(\tau_{+} / \tau_{-}\right)}{\ln (2.0 / 0.5)}$

$\tau_{+}$is the ignition delay time calculated with the increased rate coefficient and $\tau_{-}$is the ignition delay time calculated using the decreased rate expression. If the resulting sensitivity coefficient is negative this means a reaction acts to promote reactivity while a positive sensitivity coefficient means a reaction acts to inhibit reactivity.

\subsection{Rapid compression machine simulation}

Figure 9 shows a non-reactive pressure trace. Due to heat loss from the test mixture to the cold reactor walls, the pressure and temperature of the gas in the reaction chamber will decrease after the end of compression. To characterize the heat loss and to apply the heat loss conditions to simulations, a non-reactive pressure trace is required. The non-reactive pressure trace is acquired by replacing the oxygen in the oxidizer with nitrogen, so that a similar specific heat ratio is maintained, but the heat release due to exothermic oxidation reactions is eliminated. Non-reactive pressure traces are taken that correspond to each unique $p_{\mathrm{C}}$ and $T_{\mathrm{C}}$ condition studied. The pre-ignition heat loss profiles of the non-reactive and reactive mixtures should be nearly identical.

Measured pressure/time histories from each non-reactive experiment were converted to effective volume/time (V-t) histories for each test condition. For each individual test condition, the V-t profile so derived is included as a simulation input to account for the concurrent pressure and temperature change in the test mixture during experiment, including effects due to heat loss. The calculations are performed using a zero-dimensional model that and incorporates an adiabatic assumption. RCM modeling treatment is further described in $[18,23]$.

\subsection{Flame Speeds}

Laminar flame speed measurements for propene were measured in three different facilities, which are located at Princeton University (PU), Texas A\&M University (TAMU), Vrije Universiteit Brussel (VUB), Lund University (Lund) and Université de Lorraine (LRPG). Each facility is discussed briefly in the following sections.

\subsubsection{Princeton flames}

Burning rates were measured using the spherical flame method in a $10 \mathrm{~cm}$ diameter cylindrical chamber with a concentric pressure release chamber and two windows. For details on the device, see Qin and Ju [24]. Mixtures were created from propene (> 99\%), oxygen (99.5\%), helium (99.995\%), and nitrogen (99.99\%) using the partial pressure method. After allowing the mixture ten minutes to become quiescent, it is centrally ignited by a spark. High speed (8000 fps and $15000 \mathrm{fps}$ ) schlieren imaging is utilized to image the flame propagation 
up to a radius of $3 \mathrm{~cm}$. The combustion pressure rise is released to the outer chamber after the flame front has passed the edge of the viewing window.

An edge detection program and circle fitting algorithm are used to determine the flame radius from each image. The stretched propagation speed $S_{b}$ and stretch rate $\kappa$ are extracted from the radius time history and corrected for compression-induced flow effects as discussed in [25]. The un-stretched flame propagation speed $S_{b, 0}$ is then calculated through extrapolation to zero stretch using the nonlinear stretch relation (NM I, linear curvature method) recommended by Chen et al. [26] for flames characterized by Le $>1$. Extrapolation endpoints are determined iteratively by locating the range where the residuals from the fit are below a threshold value and using this range to compute a new fit. This process is repeated while decreasing the threshold until stable endpoints are found. No data analyses were performed for flames that were observed to be wrinkled due to cellular or spiraling instabilities, affected by buoyancy, or influenced by transient response of the flame speed to stretch rate. The effect of thermal radiation on apparent burning rate was also considered following the treatment of Santner et al. [27] for outwardly propagating spherical laminar flames. For all Princeton flame measurements reported herein, thermal radiation is estimated to contribute $\leq 3.7 \%$ uncertainty in apparent un-stretched laminar flame speed.

All Princeton flame speed experiments were performed at room temperature (measured as $298 \pm 2 \mathrm{~K}$ ). Atmospheric pressure experiments were performed in synthetic air. Burning rates were measured at high pressures with calculated, fixed flame temperatures of $2000 \mathrm{~K}$ in tailored $\mathrm{N}_{2} / \mathrm{He}$ dilution for equivalence ratios of 0.8 and 1.3. The $\mathrm{N}_{2} / \mathrm{He}$ ratio was adjusted to achieve stable flames and remove ignition difficulties. For $\varphi=0.8$, the $\mathrm{N}_{2} / \mathrm{He}$ ratio was 2 , and for $\varphi=1.3$, the ratio was 1 (Table 4). As shown in Section 3.3, experiments were repeated at some conditions to indicate repeatability.

Table 4: Mixture compositions for high pressure Princeton flames.

\begin{tabular}{lllll}
\hline$\varphi$ & $\% \mathrm{C}_{3} \mathrm{H}_{6}$ & $\% \mathrm{O}_{2}$ & $\% \mathrm{~N}_{2}$ & $\% \mathrm{He}$ \\
\hline 0.8 & 2.95 & 16.60 & 53.63 & 26.81 \\
1.3 & 4.04 & 14.00 & 40.98 & 40.98 \\
\hline
\end{tabular}

\subsubsection{VUB flames}

The present experiments were conducted on the heat flux installation at Vrije Universiteit Brussel (VUB). This installation has been described in detail previously [28, 29] and has been used extensively for adiabatic stabilization of premixed flames and for measuring laminar burning velocity of different gaseous fuels. Adiabatic flames were stabilized using the heat flux method on a perforated plate burner at atmospheric pressure. The heat flux burner consists of a plenum chamber and a burner plate separated by a ceramic ring for thermal insulation. They are kept at different temperatures using two separate water baths. One water bath heats the burner plate to $368 \mathrm{~K}$, while the second one ensures that the temperature of the fresh gas mixture is kept at $298 \mathrm{~K}$.

Experiments with the heat flux method are based on measuring the temperature distribution in the perforated burner plate while varying the flow rate of the fresh gas mixture. This distribution is measured by thermocouples inserted into small holes in the perforated burner plate. The temperature distribution is defined by a net heat flux to the system (net difference between the heat lost by flame to the burner plate and the heat gained by the unburned gas, while it passes through the burner plate). When the flame is stabilized at 
velocities lower than the laminar burning velocity, the heat loss is higher than the heat gain. If the flame is stabilized at a velocity higher than the laminar burning velocity, then the heat gain prevails over the heat loss. Varying the mixture flow rate, it is possible to find a velocity at which the temperature distribution is uniform, indicating that the net heat flux to the system is equal to zero (the heat loss and heat gain are equal) and the flame is adiabatic. Therefore the corresponding gas velocity is the laminar burning velocity. A more detailed description of the principles behind the heat flux method is given by Bosschaart and de Goey [30].

The gas supply system consisted of three channels for the fuel, oxygen and nitrogen. All gases were supplied by Air Liquide. The stated purity the gases was $99.95 \%$ or better. To control the flow rate and mixture compositions, Bronkhorst mass flow controllers (MFCs) were used. The MFCs were calibrated with designated gases prior to each experiment using a drum-type flow meter. It was observed that the non-linearity of the calibrating curves is different for each gas, therefore conventional calibration by air and employment of calibrating coefficients could lead to additional uncertainties and should be discouraged. A detailed analysis and quantification of burning velocity uncertainties was presented elsewhere [23, 24], and the overall accuracy of the burning velocity measurements was estimated to be better than $\pm 1 \mathrm{~cm} / \mathrm{s}$ (double standard deviation with $95 \%$ confidence level); the same uncertainty level was adopted for the present experiments. The relative error of the equivalence ratio $\varphi$ was evaluated to be $\pm 0.6 \%$. To confirm the evaluated experimental uncertainties two series of measurements at the same conditions $\left(\mathrm{C}_{3} \mathrm{H}_{6}+\right.$ air $)$ were performed. Typical differences between measured values were within $0.7 \mathrm{~cm} / \mathrm{s}$ with one outlier point deviating by $2.4 \mathrm{~cm} / \mathrm{s}$ as shown in Section 3.3.

All experiments were performed at atmospheric pressure. The mixtures studied were fuel/air mixtures and fuel $/ \mathrm{O}_{2} / \mathrm{N}_{2}$ mixtures with various dilution ratios $(\mathrm{D}=0.18,0.19,0.2$, 0.209 (air)), where $\mathrm{D}=\mathrm{O}_{2} /\left(\mathrm{O}_{2}+\mathrm{N}_{2}\right)$. An example of the mixture compositions for each of the mixtures at $\varphi=1.0$ is given in Table 5 .

Table 5: Mixture compositions at $\varphi=1.0$ for VUB flames.

\begin{tabular}{llll}
\hline $\mathrm{D}$ & $\% \mathrm{C}_{3} \mathrm{H}_{6}$ & $\% \mathrm{O}_{2}$ & $\% \mathrm{~N}_{2}$ \\
\hline 0.21 & 4.46 & 20.06 & 75.48 \\
0.20 & 4.26 & 19.15 & 76.60 \\
0.19 & 4.06 & 18.26 & 77.69 \\
0.18 & 3.85 & 17.31 & 78.85 \\
\hline
\end{tabular}

drops off and the sensitivity of the method decreases, leading to larger uncertainties.

\subsubsection{Texas A\&M flames}

Flame speed was measured using the stainless steel, constant-volume bomb at Texas A\&M University. The design and details of this vessel are explained in depth in Krejci et al. [31]. In brief, the vessel has an internal diameter of $32 \mathrm{~cm}$ and a length of $28 \mathrm{~cm}$. Given this relatively large inner diameter, flames can be measured under near-constant-pressure conditions to a diameter of $12.7 \mathrm{~cm}$. The vessel was filled with research grade Propene (99.5\%) and Primary Standard Air using the partial pressure method using a 0-1000 Torr pressure transducer. All experiments were conducted at room temperature $(296 \mathrm{~K} \pm 2 \mathrm{~K})$. The gaseous mixture was ignited by a central spark ignition system. Experiments were conducted over a wide range of equivalence ratios $(\varphi)$ from 0.7 to 1.7 . 
Experimental data were collected using a high-speed camera (Photron Fastcam SA1.1) at 3,000 fps using a Z-type Schlieren setup with a Hg lamp light source [31]. The images were processed using a MATLAB-based edge-detection program. From this program, un-stretched laminar flame speeds and Markstein Lengths were calculated using the well-known linear Markstein relation. Burned flame speeds were converted to unburned flame speeds using the density ratio calculated from the equilibrium flame chemistry. The un-stretched laminar flame speed was also calculated using the appropriate nonlinear model as shown by Chen [26]. No appreciable difference in flame speed (within the experimental uncertainty) was found between the nonlinear and the linear methods.

Experiments proved to be repeatable with a calculated uncertainty based on systematic error and random uncertainty as outlined by Krejci et al. [31] for the present facility and in general by Moffat [32]. The systematic error was based on the accuracy of the pressure transducers and the thermocouples used to conduct the experiments. The random uncertainty estimate was calculated using data from pure methane experiments to allow for enough data points for the random uncertainty to be meaningful. The total uncertainty for the mixtures was calculated to be $\pm 0.58 \mathrm{~cm} / \mathrm{s}$. A table of the measured data flame speed data is provided in the Supplementary Material.

\subsubsection{LRPG flames}

The measurements of laminar burning velocities were performed at LRGP (CNRSUniversité de Lorraine) using a heat flux burner adapted from VUB. The apparatus has been modified to the study of gaseous and liquid fuels and allow an increase of the fresh gas temperature up to $398 \mathrm{~K}$. The experimental device has been described previously [33,34]. The principle is similar to that used at VUB described above (Section 2.10.2). To allow the investigation of higher initial temperatures, the plenum chamber is encompassed by a thermostatic oil jacket, the temperature of which is set to the desired initial temperature of the unburned gas mixture. The circumference of the burner plate is heated with thermostatic oil set to about $50 \mathrm{~K}$ above the temperature of the unburned gas mixture so that the heat gain of the unburned gas mixture from the burner can compensate for the heat loss from the flame to the burner necessary to stabilize the flame.

The burning velocity of propene/air mixtures has been investigated under atmospheric pressure for fresh gas temperature $298 \mathrm{~K}, 358 \mathrm{~K}$, and $398 \mathrm{~K}$ and equivalence ration ranging from 0.5 to 2 . The air was considered as a 21/79 vol. oxygen/nitrogen blend. Gas flow rates were measured using Bronkhorst High-Tech Mass Flow Controllers (MFC). Oxygen and nitrogen were delivered by Messer (purity $>99.995 \%$ vol.). Propene was provided by Air Liquide (purity $>99.5 \%$, without any noticeable content of other hydrocarbons).

The uncertainty in the laminar burning velocity can be first attributed to the uncertainty in the mass flow measurements (around $0.5 \%$ for each MFC) which can lead to a global uncertainty of $1.5 \%$ and around $1 \%$ in equivalence ratio. The uncertainty in reading the temperature with thermocouples which could lead to an error of around $0.2 \mathrm{~cm} / \mathrm{s}$ in the laminar burning velocity, and to errors due directly to flame distortions, such as edge effects (estimated around $0.2 \mathrm{~cm} / \mathrm{s}$ ). In the case of very rich mixtures, the change in the curvature of the temperature profile with the gas flow

\subsubsection{Lund flames}

Experiments were performed on a heat flux setup at Lund University. The general features of a heat flux burner and the principle of the heat flux method was described in previous section on VUB flames, see references therein. Thermostated waterbaths were set to 
$368 \mathrm{~K}$ for the burner plate and $298 \mathrm{~K}$ for the plenum chamber, and measurements were performed at atmospheric pressure. The setup in Lund has previously been described in detail [35].

Gas mixtures were composed of propene, oxygen and nitrogen (AGA), metered by Bronkhorst Mass Flow Controllers (MFCs). The MFCs were calibrated for the specific gases using a Bios Drycal piston meter, model Definer 220. The main experimental uncertainties are from uncertainties in gas mixture composition and scatter in temperature reading from thermocouples in the burner plate.

Uncertainties in equivalence ratio are typically in the range 0.01 to 0.04 , increasing within this range when going from lean to rich conditions. These uncertainties are calculated from the accuracy of the flows of oxidizer and fuel, and are quantified in the same manner as by Bosschaart and de Goey [30]. The accuracy of the flows of oxidizer and fuel are taken into account also for the uncertainties in laminar burning velocity. In addition the scatter in the temperature distribution of the thermocouples are evaluated. The standard deviation in the temperature distribution from the thermocouples is calculated by a least square fit. At the present conditions the overall uncertainty in laminar burning velocities are typically lower than $\pm 0.5 \mathrm{~cm} / \mathrm{s}$.

\subsection{Flame speed simulation}

Flame speed simulations were performed using the Premix module [36] of CHEMKINPRO [37]. Performing a flame speed simulation with a full low-temperature mechanism is computationally costly. Therefore, a high-temperature version was used. The high-temperature mechanism was created by removing all the species and reactions that irrelevant under flame conditions. Species removed include large alkyl-peroxy radicals, hydroperoxyl-alkyl radicals, ketohydroperoxide species etc. Extensive testing was carried out for AramcoMech 1.3 [38] and the high temperature mechanism results in the same predictions as the complete mechanism but at a considerably reduced computational cost. As discussed by Metcalfe et al. [38] simulations were converged to a grid-independent solution of approximately 1000 grid points. GRAD and CURV values of 0.02 were assigned. The mixture-average model for calculating the transport coefficients was used. Inclusion of the more accurate multicomponent model was deemed unnecessary, as in general it was found that the predicted flame speeds were within $1 \mathrm{~cm} / \mathrm{s}$ of the mixture-averaged solution, while increasing the computational time considerably. Thermal diffusion (Soret effect) was accounted for in the simulations. Flame speed sensitivity analyses were performed using CHEMKIN-PRO's inbuilt utility, which calculates first-order sensitivity coefficients for the predicted mass flow rate, which corresponds to the flame speed.

\section{Results}

The experimental ignition delay time and laminar flame speed measurements are shown in the Sections below and are compared with the chemical kinetic mechanism presented in Part I [1]. The current mechanism is described in detail in that study, briefly the important reactions were identified through sensitivity and flow rate analyses. Rate constants for the highlighted reactions were adopted from recent comprehensive theoretical and experimental studies where available or were otherwise estimated.

\subsection{Ignition delay time results}

Ignition delay time measurements from six different shock tubes and two different rapid compression machines (RCMs) are presented. Ignition delay times are displayed on 
Arrhenius-type plots, with the ignition delay on a log scale plotted as a function of reciprocal reflected-shock temperature in the case of the shock tube data and compressed temperature for the RCM. The experimental data are compared to the predictions of the current mechanism and in some cases the previous mechanism (AramcoMech 1.3 [38]). The solid symbols represent data obtained from NUI Galway, vertically half-filled symbols from Stanford, open symbols from TAMU, crossed open symbol from RPI, open symbols with a vertical line from UConn and horizontally half-filled symbols from KAUST. In general, there is good agreement among the predictions of the current mechanism and the experimental measurements. The performance of the current mechanism is greatly improved over AramcoMech 1.3 [38]. The mixture numbers referenced in the legend of all plots in this section correspond to the mixture number included in Table 3.

\subsubsection{Comparison among different facilities}

Some experiments were performed in different experimental facilities at common conditions allowing facility-to-facility comparison. Figure 10 compares ignition delay time data from different shock tube and RCM facilities. There is good agreement between the results from the shock tubes. Experiments of common mixtures from the different facilities are within $20 \%$ of each other, Figs. 10(a) and (b).

Best fits to ignition delay time measurements from individual shock tube facilities, illustrating the repeatability of measurements made in a single facility, exhibit $1 \sigma$ scatter about those best fits of $\pm 5-10 \%$ in all cases, well within the presently cited uncertainties for shock tube ignition delay $( \pm 15-20 \%)$ which take into account estimates of systematic uncertainties that potentially do not contribute to statistical scatter (e.g., systematic errors in calculated postshock conditions).

Best fits to compilations of ignition delay data from shock tube experiments carried out at independently in multiple facilities at common conditions, show $1 \sigma$ scatter ranging from < $\pm 10 \%$ to $\pm 15 \%$, Figs. 10 (a) and (b). For example, the $1 \sigma$ scatter about the best fit in Fig. 10(a) is $\pm 13 \%$, nearly a worst case among the shock tube results presented here. This suggests that $\pm 20-30 \%$ can be viewed as a metric for the reproducibility. This suggests that (with $95 \%$ confidence) independent measurements of high-temperature shock tube ignition delay times reported by different laboratories are generally reproducible within $\pm 20-30 \%$.

In general RCMs are designed differently and as such each will have different heat loss characteristics, therefore they will have different ignition delay times for the same mixture, as shown in Fig. 10(c). A comparison of reactive pressure profiles under similar conditions from NUI Galway and UConn is shown in Fig. 10(d). The Galway RCM exhibits significantly more heat loss than the UConn facility; this is one possible reason why the NUI Galway RCM yields longer ignition times than the UConn facility. Using the volume history for each experiment as input to kinetic simulations allows each RCM to be simulated appropriately, incorporating the specific heat loss characteristics for each facility. 


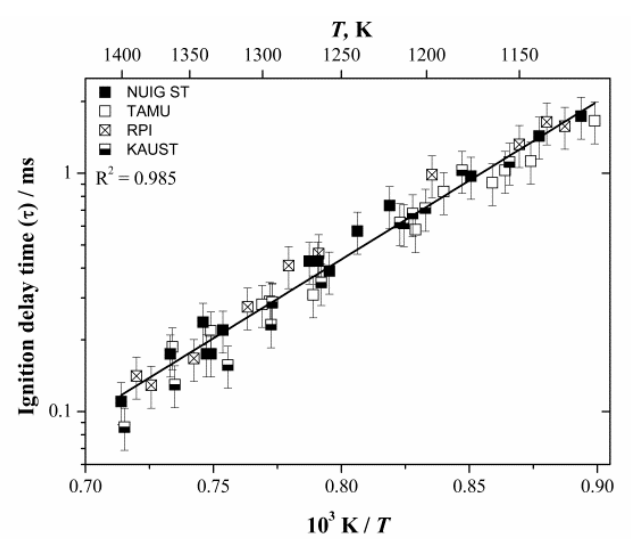

(a) Fuel/air, $p=10 \mathrm{~atm}, \varphi=1.0$, line: linear fit.

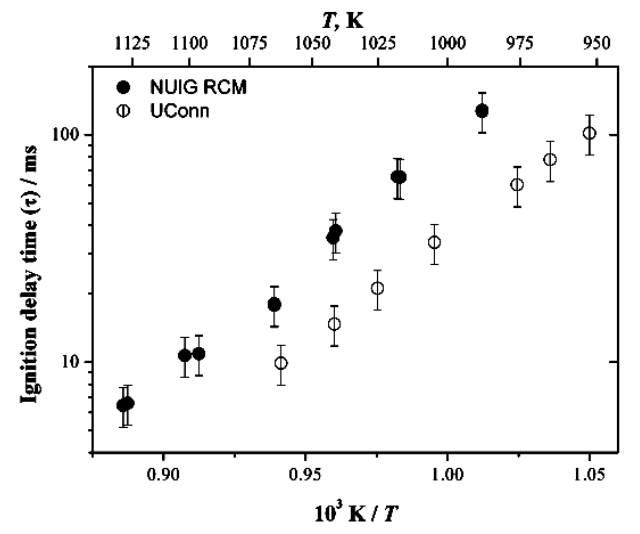

(c) $\mathrm{C}_{3} \mathrm{H}_{6} / 12 \% \mathrm{O}_{2}, \varphi=1.0, \mathrm{p}=10$ atm.

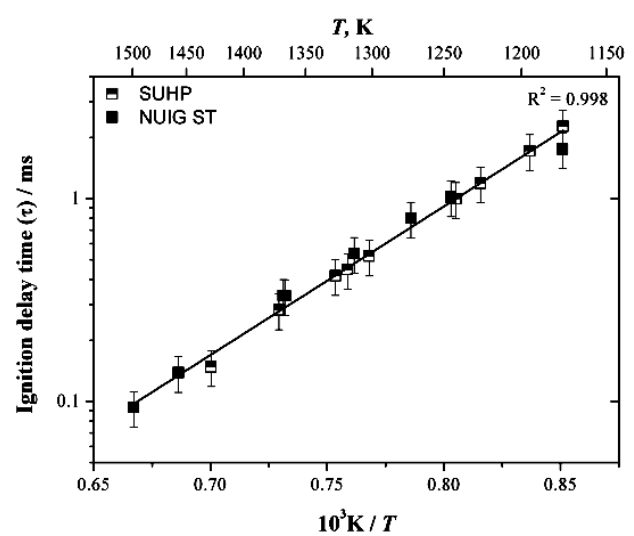

(b) $\mathrm{C}_{3} \mathrm{H}_{6} / 4 \% \mathrm{O}_{2}, p=40$ atm, $\varphi=1.0$ line: linear fit.

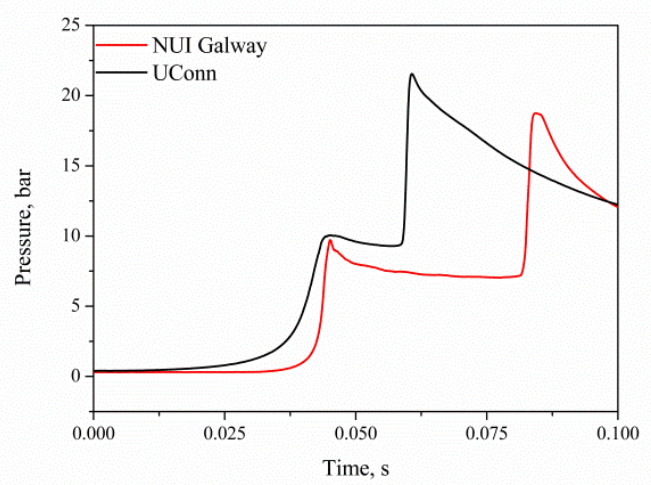

(d) $p$ profiles from (c), $T_{c} \approx 1040 \mathrm{~K}$.

Figure 10: Comparison of propene IDTs from shock tubes and RCMs. Symbols: experimental data.

\subsubsection{Pressure dependence}

Figures 11 and 12 show that reactivity increases with pressure at all equivalence ratios and all levels of dilution presented in this study. As the pressure increases so does the absolute concentration of reactants, resulting in an increase in the overall reactivity of the system. The mechanism is able to accurately predict the influence of pressure on ignition delay times over a wide range of temperatures, equivalence ratios and levels of dilution.

Figure 11 shows the effect of pressure on ignition delay times obtained in shock tubes and RCMs for fuel/air mixtures at $\varphi=0.5,1.0$, and 2.0. The experimental results show that ignition delay times decrease with increasing pressure at all equivalence ratios. There is approximately a factor of twenty difference in times measured at 10 atm to those measured 40 atm at $\varphi=1.0$ and $900 \mathrm{~K}$, Fig. 11(a). Sensitivity analyses were carried out at $950 \mathrm{~K}$ at 10 and $40 \mathrm{~atm}$ for a stoichiometric mixture in order to determine the important controlling reactions at these conditions. The results are included in Fig. 13(a). 


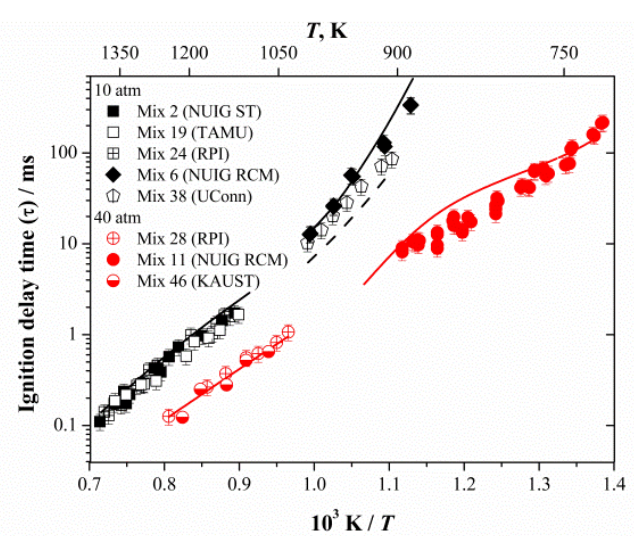

(a) $p=10$ and 40 atm, $\varphi=1.0$.

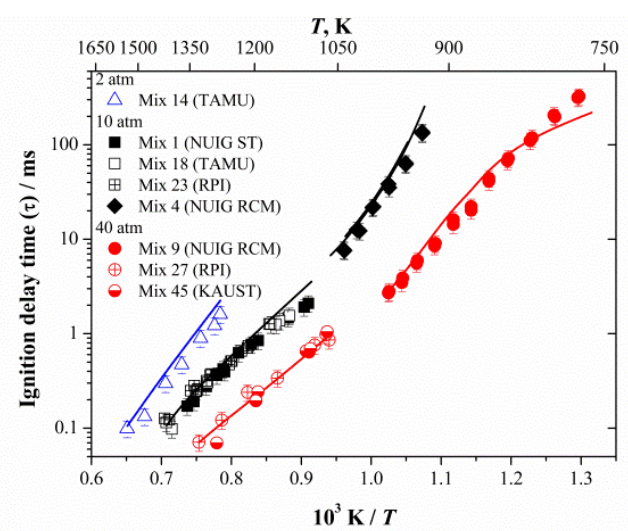

(b) $p=2,10$, and 40 atm, $\varphi=0.5$.

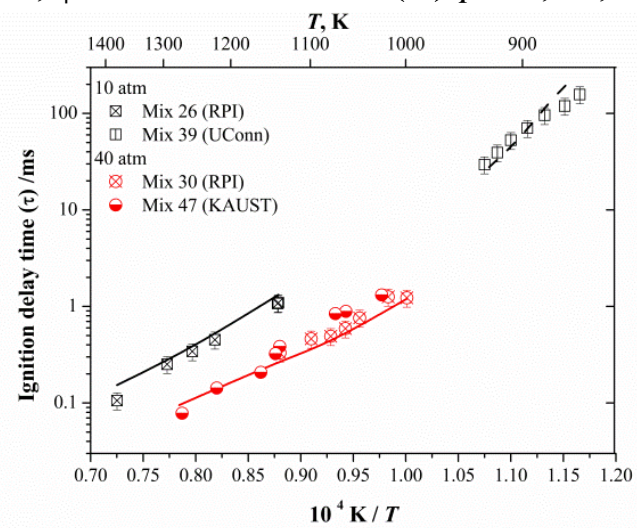

(c) $p=10$ and 40 atm, $\varphi=2.0$.

Figure 11: Influence of pressure on propene IDTs from shock tubes and RCMs for fuel/air mixtures as outlined in Table 3. Symbols: experimental data; lines: simulations, dashed lines: simulation of UConn measurements.

At lower temperatures and higher pressures the reaction of atomic hydrogen and molecular oxygen proceeds via the collisionally stabilized pathway $\dot{\mathrm{H}}+\mathrm{O}_{2}(+\mathrm{M}) \leftrightarrow \mathrm{HO}_{2}(+\mathrm{M})$ not via the chain branching $\dot{\mathrm{H}}+\mathrm{O}_{2} \leftrightarrow \ddot{\mathrm{O}}+\dot{\mathrm{O}} \mathrm{H}$ channel. The resulting hydroperoxyl radical forms hydrogen peroxide which decomposes to form two hydroxyl radicals. Figure 13(a) shows that $\mathrm{HO}_{2}$ decomposition expresses a higher sensitivity at $40 \mathrm{~atm}$ than at $10 \mathrm{~atm}$ at $950 \mathrm{~K}$. Other sensitive reactions include hydrogen abstraction reactions by hydroxyl radicals from propene which results in the generation of three $\dot{\mathrm{C}}_{3} \mathrm{H}_{5}$ radicals. The resulting allyl radical $\left(\dot{\mathrm{C}}_{3} \mathrm{H}_{5}-\mathrm{a}\right)$ is consumed by reactions with hydroperoxyl. The rate constants for the reactions forming allyloxy $\left(\mathrm{C}_{3} \mathrm{H}_{5} \mathrm{O}\right)$ and hydroxyl radical, allyl-hydroperoxide $\left(\mathrm{aC}_{3} \mathrm{H}_{5} \mathrm{OOH}\right)$ and the resulting allyloxy radical decomposition are pressure dependent. The 2-propenyl radical reacts with molecular oxygen via promoting chain branching reactions giving acetonyl radical and atomic oxygen $\left(\dot{\mathrm{C}}_{3} \mathrm{H}_{5}-\mathrm{t}+\mathrm{O}_{2} \leftrightarrow \mathrm{CH}_{3} \mathrm{COC}_{2} \mathrm{H}_{2}+\ddot{\mathrm{O}}\right)$

Figure 12 shows the effect of pressure on dilute mixtures at pressures of 2-40 atm. Figure 13(b) shows the results of two sensitivity analyses carried out at $1550 \mathrm{~K}$ and 2 and $10 \mathrm{~atm}$. The $\dot{\mathrm{H}}+\mathrm{O}_{2} \leftrightarrow \ddot{\mathrm{O}}+\dot{\mathrm{OH}}$ reaction is the most promoting reaction at both 2 and $10 \mathrm{~atm}$ and the sensitivity coefficient has been reduced by a factor of two for overall clarity. The most inhibiting reactions under both sets of conditions are the reactions of hydrogen atoms with propene $\left(\mathrm{C}_{3} \mathrm{H}_{6}+\dot{\mathrm{H}}\right)$. Reactions that consume atomic hydrogen compete with the main chain branching reaction between hydrogen atom and molecular oxygen and inhibit reactivity in this pressure and temperature range. 


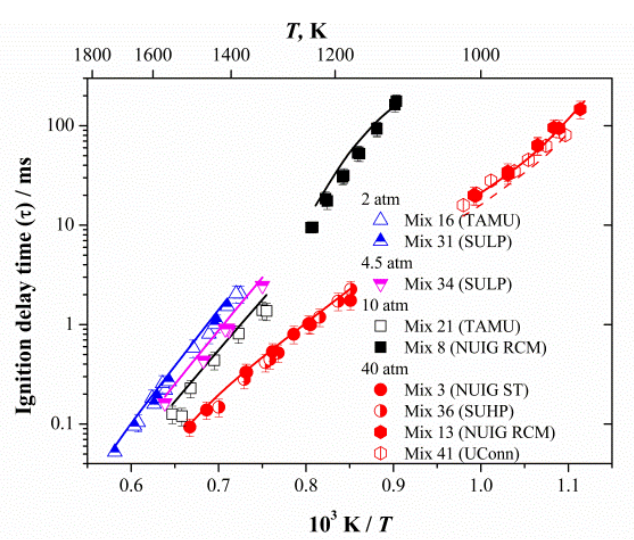

(a) $\varphi=1.0, p=2,4.5,10$, and $40 \mathrm{~atm}$ $\mathrm{C}_{3} \mathrm{H}_{6} / 4 \% \mathrm{O}_{2}$.

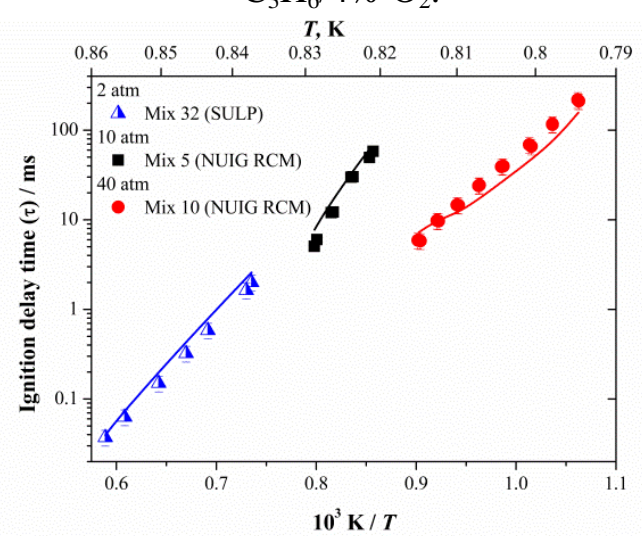

(c) $\varphi=0.5, p=2,10$, and $40 \mathrm{~atm}$ $\mathrm{C}_{3} \mathrm{H}_{6} / 4 \% \mathrm{O}_{2}$.

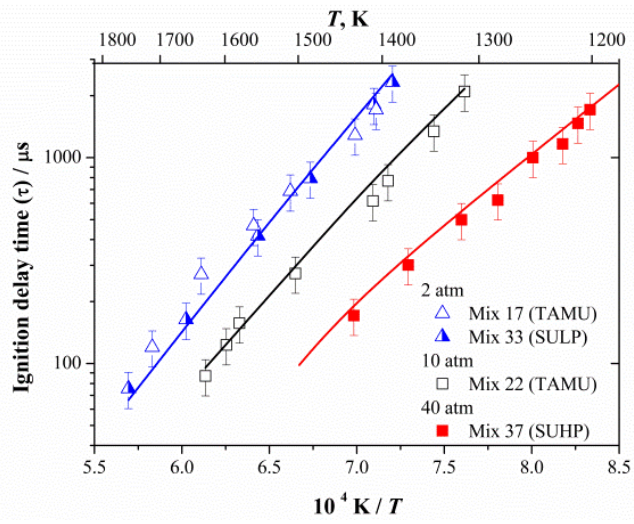

(b) $\varphi=2.0, p=2,10$ and 40 atm $\mathrm{C}_{3} \mathrm{H}_{6} / 4 \%$

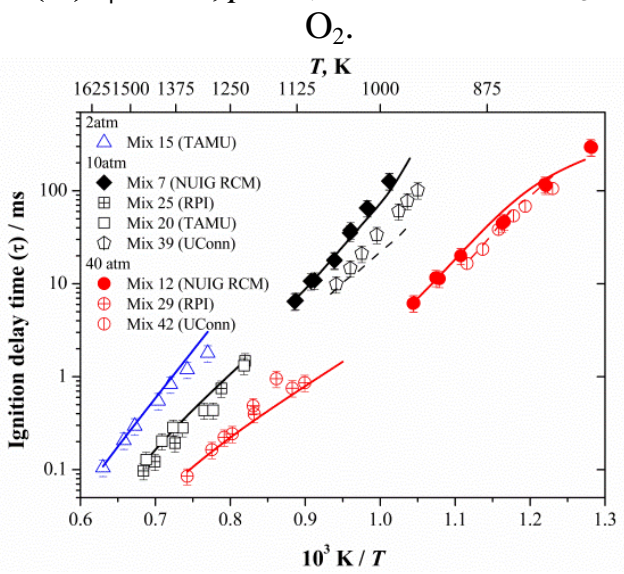

(d) $\varphi=1.0, p=2,10$ and 40 atm $\mathrm{C}_{3} \mathrm{H}_{6} / 12 \% \mathrm{O}_{2}$.

Figure 12: Influence of pressure on propene IDTs under dilute conditions, mixtures as outlined in Table 3. Symbols: experimental data; lines: simulations, dashed lines: simulation of UConn measurements.

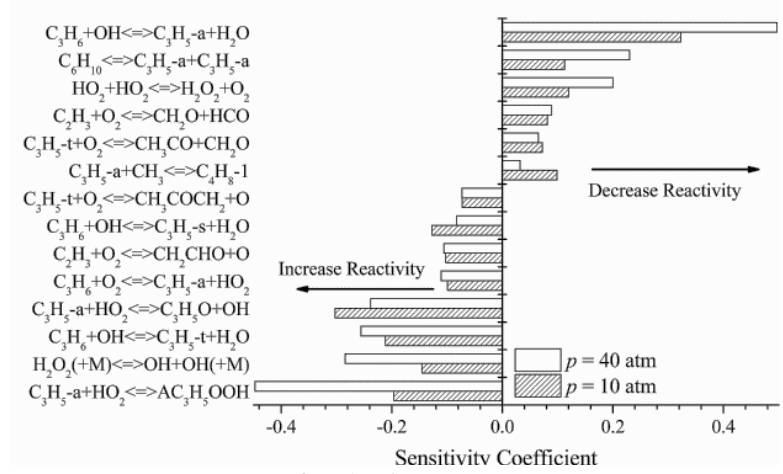

(a) $\varphi=1.0$, fuel/air, $T=950 \mathrm{~K}$.

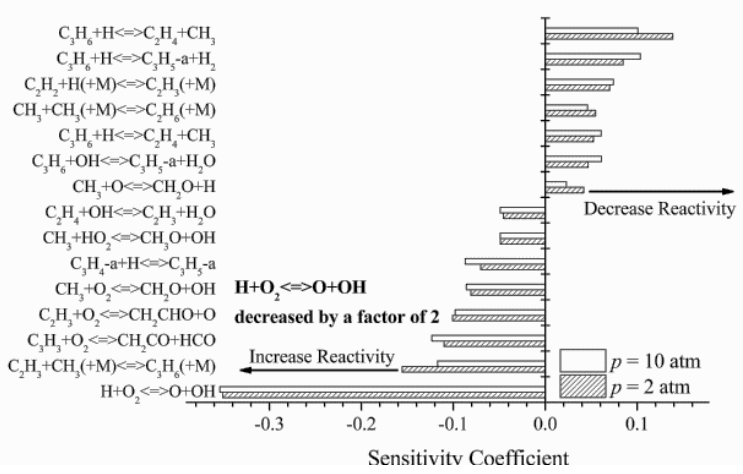

(b) $\varphi=1.0, \mathrm{C}_{3} \mathrm{H}_{6} / 4 \% \mathrm{O}_{2}, T=1550 \mathrm{~K}$.

Figure 13: Sensitivity analyses to ignition delay times performed at $\varphi=1.0$ at 950 and $1550 \mathrm{~K}$ at various pressures.

\subsubsection{Equivalence ratio dependence}

Figure 14 shows the influence of equivalence ratio on ignition delay times. Dilute mixtures at 2 atm are included in Fig. 14(a), while fuel/air mixtures at 10 atm are shown in Fig. 14(b). The mechanism can accurately predict the influence of equivalence ratio across the range of pressure, temperatures and levels of dilutions investigated in this study. 


\section{2 atm}

At temperatures above $1450 \mathrm{~K}$, ignition delay times are fastest for fuel-lean mixtures and slowest for fuel-rich mixtures, Fig. 14(a). In order to determine the controlling chemistry under high-temperature low-pressure conditions a brute-force sensitivity analysis was carried out for each equivalence ratio at 2 atm and $1550 \mathrm{~K}$, it is depicted in Fig. 14(c). As discussed previously at high temperatures the most promoting reaction is the $\dot{\mathrm{H}}+\mathrm{O}_{2} \leftrightarrow \ddot{\mathrm{O}}+\dot{\mathrm{O} H}$ while the $\mathrm{C}_{3} \mathrm{H}_{6}+\dot{\mathrm{H}}$ reactions are the most inhibiting. Under fuel-rich conditions there is increased competition for atomic hydrogen from reactions involving the fuel which compete with the main chain branching reactions between hydrogen atom and molecular oxygen. Therefore, reactivity increases from fuel-rich to fuel lean. The effect of equivalence ratio on ignition delay time decreases with temperature.

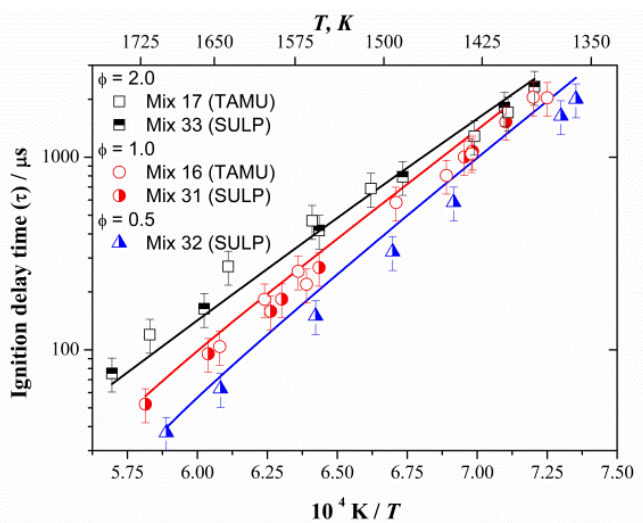

(a) $\mathrm{C}_{3} \mathrm{H}_{6} / 4 \% \mathrm{O}_{2}, \varphi=2.0,1.0$, and $0.5, p$ $=2 \mathrm{~atm}$.

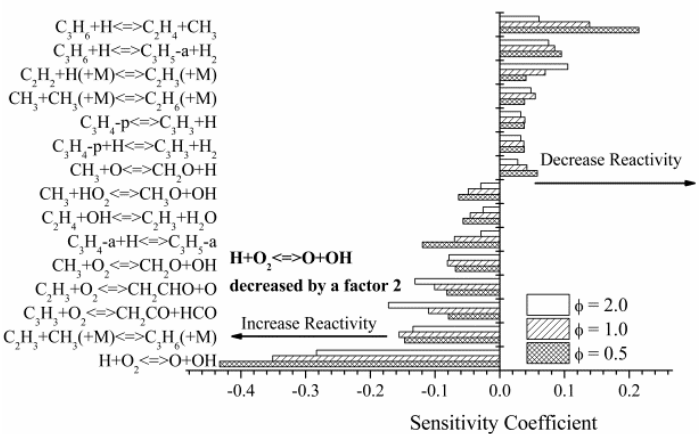

(c) Brute-force sensitivity analysis, $p=2$ atm, $T=1550 \mathrm{~K}$.

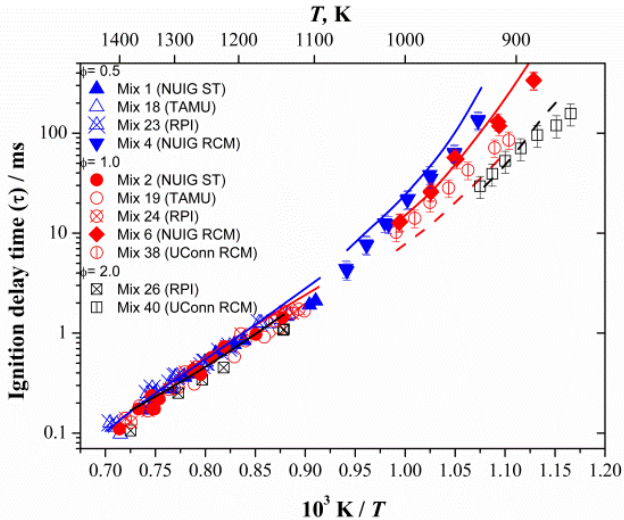

(b) Fuel/air $\varphi=2.0,1.0$, and $0.5 p=10$

atm.

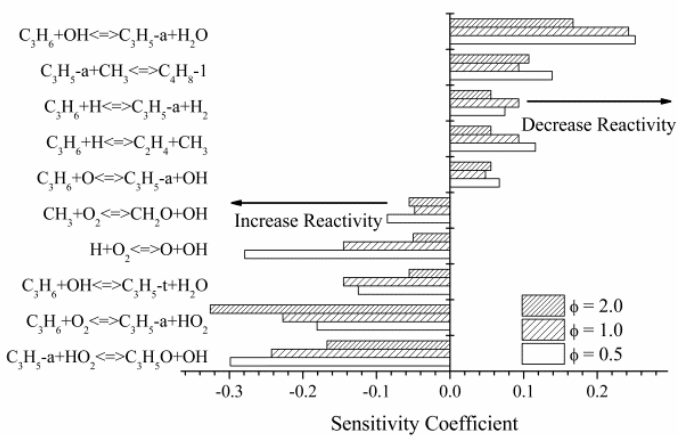

(d) Brute-force sensitivity analysis, $p=10$ atm, $T=1250 \mathrm{~K}$.

Figure 14: Effect of equivalence ratio on propene IDTs from shock tubes and RCMs under dilute conditions for $p=2$ atm and fuel/air for $p=10$ atm. Mixtures as outlined in Table 3. Symbols: experimental data; lines: simulations, dashed lines: simulation of UConn measurements.

\section{0 atm}

The 10 atm shock tube IDT data in Fig. 14(b) shows little or no effect of equivalence ratio. In this temperature regime $(\sim 1100-1450 \mathrm{~K})$ there is a crossover between the low and hightemperature reactions controlling. The sensitivity analysis carried out at $10 \mathrm{~atm}$ and $1250 \mathrm{~K}$ shown in Fig. 14(d) highlights that in this intermediate temperature regime there is a decreased influence of the $\dot{\mathrm{H}}+\mathrm{O}_{2} \leftrightarrow \ddot{\mathrm{O}}+\dot{\mathrm{O}} \mathrm{H}$ reaction and an increased sensitivity to reactions involving 
the fuel in comparison to Fig. 14(c). The crossover in reactivity is predicted by the mechanism.

\section{0 atm}

Figure 15 shows the influence of equivalence ratio on ignition delay times at 40 atm for fuel/air mixtures in both shock tubes and RCMs. In the relatively low temperature regime studied in the RCM, reactivity is governed by reactions of the fuel as shown in Fig. 15 (c) and reactivity increases from fuel-lean to fuel-rich mixtures. In this temperature regime sensitive reactions include allyl radical recombination to form 1,5-hexadiene $\left(\dot{\mathrm{C}}_{3} \mathrm{H}_{5}\right.$-a $+\dot{\mathrm{C}}_{3} \mathrm{H}_{5}$-a $\leftrightarrow$ $\mathrm{C}_{6} \mathrm{H}_{10}$ ), reactions involving the fuel including $\mathrm{C}_{3} \mathrm{H}_{6}+\dot{\mathrm{O}} \mathrm{H}$, and $\mathrm{H}_{2} \mathrm{O}_{2}$ decomposition to form two hydroxyl radicals. Similar to the 10 atm results there is only a small influence of equivalence ratio under shock tube conditions, Fig. 15(b). The shock tube measurements were carried out within the temperature regime where there is a crossover in reactivity controlling reactions between reactivity controlled by the fuel, or the $\mathrm{O}_{2}$ concentration via the $\dot{\mathrm{H}}+\mathrm{O}_{2} \leftrightarrow \ddot{\mathrm{O}}$ + OH reaction that controls reactivity at high-temperatures, Fig. 15 (c).

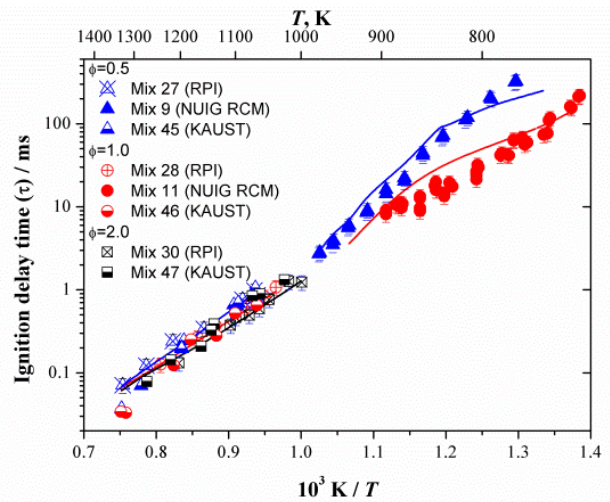

(a) Shock tube and RCM.

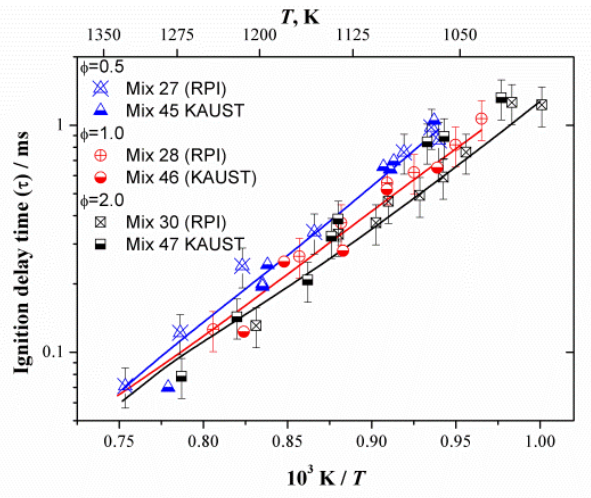

(b) Shock tube.

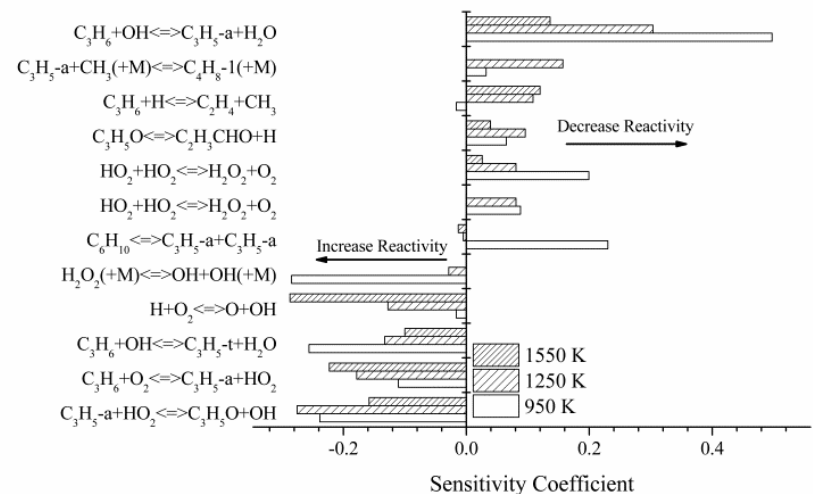

(c) Brute-force sensitivity analysis, $\varphi=1.0, T=950,1250$, and $1550 \mathrm{~K}$.

Figure 15: Effect of equivalence on propene IDTs from shock tubes and RCMs under fuel/air conditions at 40 atm. Mixtures as outlined in Table 3. Symbols: experimental data; lines: simulations. 


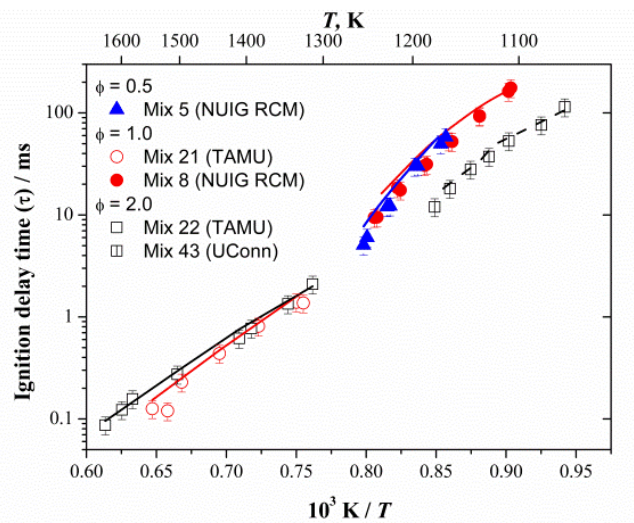

(a) $\mathrm{C}_{3} \mathrm{H}_{6} / 4 \% \mathrm{O}_{2}, \varphi=2.0,1.0$, and 0.5 , $p=10 \mathrm{~atm}$.

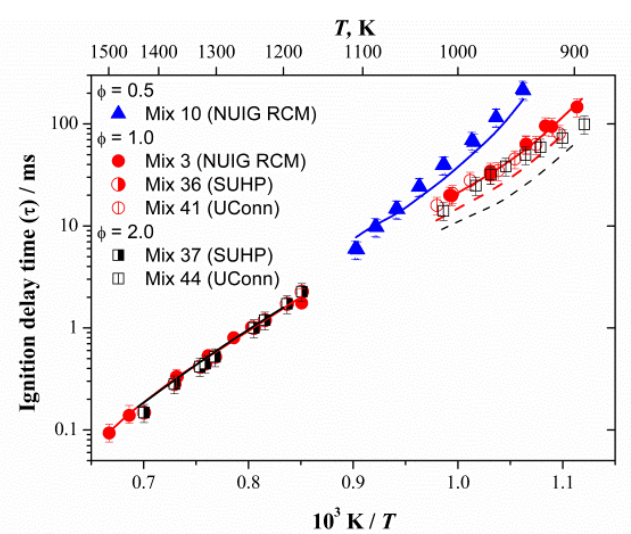

(b) $\mathrm{C}_{3} \mathrm{H}_{6} / 4 \% \mathrm{O}_{2}, \varphi=2.0,1.0$, and 0.5 , $p=40$ atm.

Figure 16: Effect of equivalence ratio on propene IDTs from shock tubes and RCMs under dilute conditions for $p=10$ and 40 atm. Mixtures as outlined in Table 3. Symbols: experimental data; lines: simulations, dashed lines: simulation of UConn measurements.

Figure 16 shows the influence of equivalence ratio on dilute mixtures at elevated pressures. At high-temperatures ignition delay times are fastest for stoichiometric mixtures and reactivity converges at approximately $1320 \mathrm{~K}$, Fig 16(a). There is little to no effect of equivalence ratio in the shock tube at 40 atm as shown in Fig 16(b).

\subsubsection{Effect of dilution}

Reactivity increases with decreased dilution at the range of conditions considered. At 40 atm the ignition delay time at $900 \mathrm{~K}$ increases from $\approx 10 \mathrm{~ms}$ for the fuel/air mixture to $\approx 20 \mathrm{~ms}$ for the $85 \%$ diluent to $\approx 200 \mathrm{~ms}$ for the $95 \%$ diluent mixture, Fig. 17(b). The mechanism accurately predicts the influence of dilution in the shock tube at $4.5 \mathrm{~atm}$ and in the RCM at 40 atm, Figs. 17(a) and (b), respectively.

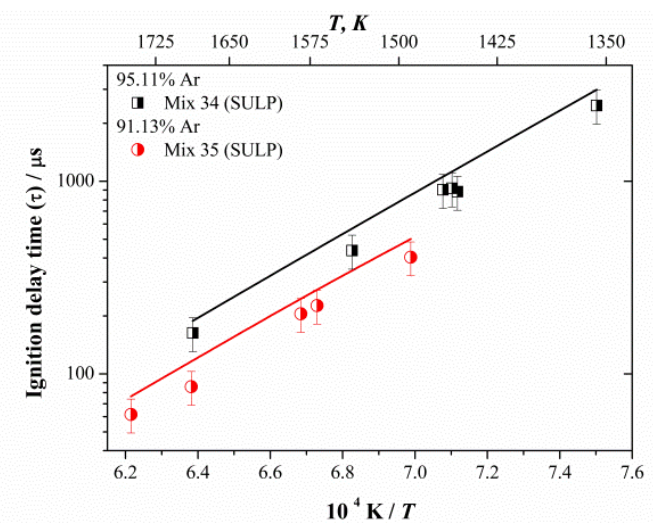

(a) ST: $\varphi=1.0, p=4.5$ atm.

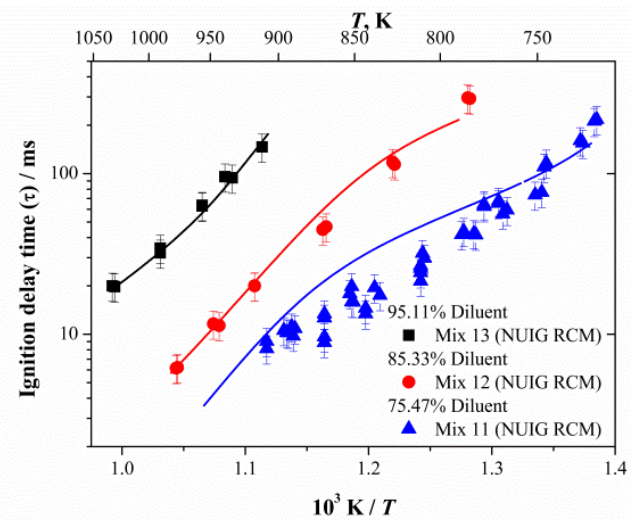

(b) RCM: $\varphi=1.0, p=40$ atm.

Figure 17: Effect of dilution on selected propene IDTs from shock tubes and RCMs and 4.5 and 40 atm. Mixtures as outlined in Table 3. Symbols: experimental data; lines: simulations.

\subsection{Previous mechanism performance}

Figure 18 compares the performance of the improved chemical kinetic scheme with AramcoMech 1.3 against experimental data from shock tubes and the NUI Galway RCM. The mixtures included are $\varphi=1$, fuel/air at 10 and $40 \mathrm{~atm}$. A detailed discussion of the changes to 
the important rate constants that have taken place since the publication of the previous mechanism [38] is included in Part I [1].

As stated in Part I AramcoMech 1.3 was validated against $\mathrm{C}_{0}-\mathrm{C}_{2}$ data only and was not designed for the accurate prediction of combustion characteristics of higher order species. Figure 18 shows that AramcoMech 1.3 greatly over-predicts reactivity at lower temperatures at 10 and $40 \mathrm{~atm}$ while it under-predicts reactivity at higher temperatures. At $900 \mathrm{~K}$ and 40 atm the prediction of AramcoMech 1.3 is approximately twenty times faster than the predictions of the current mechanism. Figure 18 shows that the previous mechanism predicted NTC-like behavior that is neither predicted by the current kinetic scheme nor observed in the experimental measurements. The changes that had the biggest effect on the performance of the mechanism under these conditions were; inclusion of pressure dependent rate constants for the $\mathrm{C}_{3} \mathrm{H}_{6}+\mathrm{HO}_{2}$ reactions [39][40] and $\dot{\mathrm{C}}_{3} \mathrm{H}_{5}-\mathrm{a}+\mathrm{HO}_{2}$ reactions [41], inclusion of rate constants for allyl radical recombination, and changes to the rate constants of the $\mathrm{C}_{3} \mathrm{H}_{6}, \dot{\mathrm{C}}_{3} \mathrm{H}_{5}-\mathrm{t}$, and $\dot{\mathrm{C}}_{3} \mathrm{H}_{5}-\mathrm{S}+\mathrm{O}_{2}$ reactions.

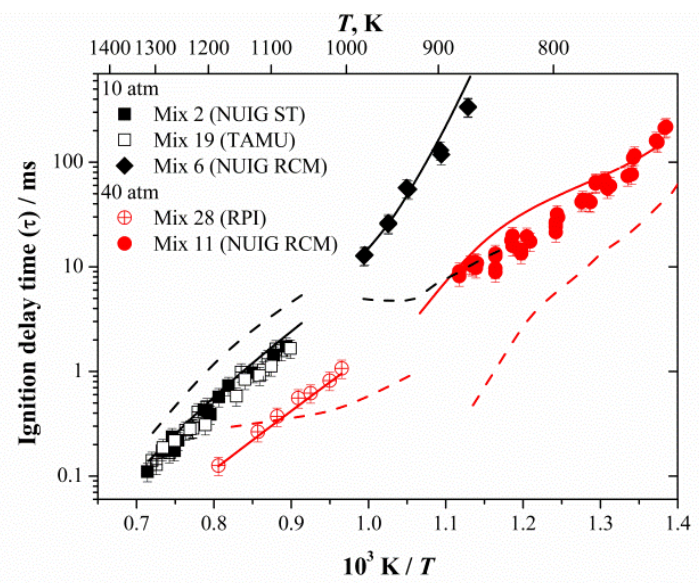

Figure 18: Comparison of current mechanism and AramcoMech 1.3. Fuel/air mixture, $p=10$ and 40 atm. Symbols: experimental data. Lines: — current mechanism and - - AramcoMech 1.3. [38].

\subsection{Laminar flame speed results}

Laminar flame speeds of propene in air at 1 atm and $298 \mathrm{~K}$ taken during the course of this study are compared with literature measurements in Fig. 19(a) using different methods.

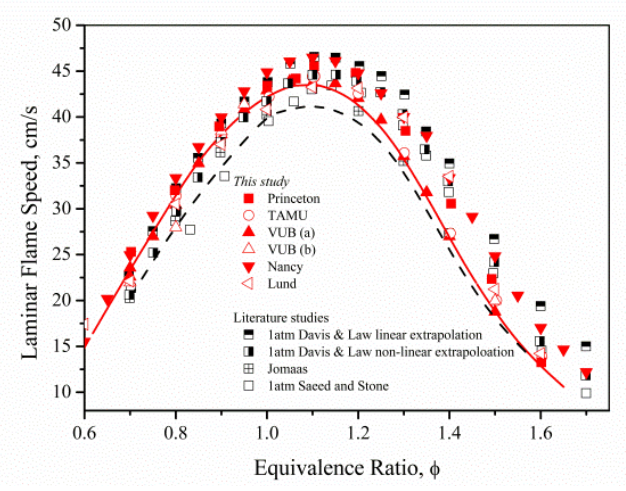

(a)

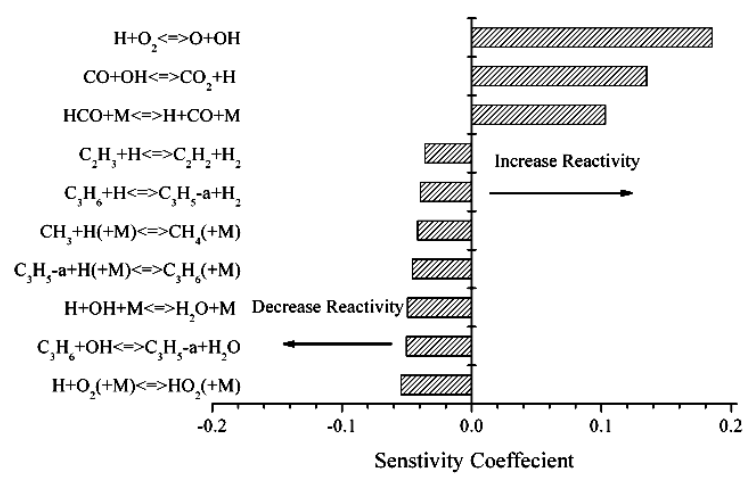

(b)

Figure 19: $\mathrm{C}_{3} \mathrm{H}_{6} /$ air laminar flame speed at $p=1$ atm Symbols: experimental data, lines: _ current mechanism and - - AramcoMech 1.3 [38]. Flame speed sensitivity analysis at $\varphi=0.95$. 
Data from PU, TAMU, Jomaas et al. [6], and Saeed et al. [7] were all measured using spherically propagating flames. However, the flame speed extrapolation methods are all different. PU data included the effect of flow compression but the data from TAMU and Jomaas et al. [6] did not. This correction is recommended when the flame radius is larger than $30 \%$ of the chamber radius or the chamber is cylindrical [25]. For a small chamber size, the inclusion of flow correction will increase flame speed. Data from Saeed et al. [7] were estimated from the pressure-time history, which could be affected by flame instability and heat loss. There are some inconsistencies in the flame speed extrapolation using spherical flames with different chamber shapes and sizes especially when the mixture Lewis number is much less or larger than unity [42]. Conservative estimates of radiation-induced uncertainty in spherically expanding flames [27] predict a maximum inhibition of $3.7 \%$ for the PU measurements and $6.1 \%$ for the TAMU measurements. Radiation heat loss has a stronger effect in TAMU flames due to the large flame size utilized. However, the use of a large flame size in TAMU reduces extrapolation uncertainty due to the low stretch rate. Data from Davis et al. [5] were obtained using counterflow flames without nonlinear extrapolation. Data without appropriate non-linear extrapolation may lead to higher flame speeds.

Heat flux burners were used for measurements from VUB, Lund, and LRPG. These burners typically report lower uncertainty than spherical and counterflow flames due to the reduced stretch effects. However, the flat flames may introduce uncertainties due to the flame instability and reduced sensitivity of temperature gradient to flow velocity, especially on the rich side. Mass Flow Controllers (MFCs) also influence the overall uncertainties, the relative errors in mass flows increases when smaller flows are produced [30].

Under fuel-lean conditions the data from PU, VUB, and TAMU, LRPG, and Lund show good agreement with each other and with the mechanism predictions. However, under fuelrich conditions only the VUB and TAMU measurements agree with each other and the model prediction. PU data shows good agreement with the data of Davis et al. [5] but are faster than the VUB and TAMU data. Measurements from LRPG are consistent with Davis et al. [5] and the Lund measurements under rich conditions, and measurements from Lund agree with the fastest data for some conditions, and with the slowest data for other conditions. Disagreement for rich measurements are expected for spherical and counterflow flames, as uncertainties due to extrapolation are larger for mixtures with Le $<1$ [26], corresponding to fuel rich mixtures for propene. Uncertainty caused by radiation induced heat loss in spherical flames is larger for fuel-rich flames due to the increase of radiative species, possibly contributing to scatter between facilities. Uncertainties in equivalence ratio for the heat flux burner are typically range from 0.01 to 0.04 which increases as $\varphi$ increases [30]. Note that for other gaseous or liquid fuels, such methane [33], ethanol [43] or $n$-heptane [34], there is a notably better agreement between the measurements made using heat flux method than in the present case. In comparison to the current mechanism, AramcoMech 1.3 under-predicts the flame speed of the new experimental data across the range of equivalence ratios. However, it shows reasonable agreement with the data of Jomaas et al. [6].

The scatter in new measurements represents the uncertainty of the flame speed measurements using different methods and facilities. Flame speed measurements and predictions cannot presently be resolved beyond this uncertainty. For more details on uncertainties of flame speed measurements, we refer the reader to a recent review paper Error! Reference source not found.

As shown in Fig. 19(b), many of the important reactions highlighted in the sensitivity analysis are $\mathrm{H}_{2} / \mathrm{CO}$ sub-mechanism reactions such as reactions between atomic hydrogen and molecular oxygen carbon monoxide reacting with hydroxyl radical etc. Propene reactions 
highlighted as sensitive include $\mathrm{C}_{3} \mathrm{H}_{6}+\mathrm{O} H \leftrightarrow \dot{\mathrm{C}}_{3} \mathrm{H}_{5}-\mathrm{a}+\mathrm{H}_{2} \mathrm{O}$ and $\dot{\mathrm{C}}_{3} \mathrm{H}_{5}-\mathrm{a}+\dot{\mathrm{H}}(+\mathrm{M}) \leftrightarrow \mathrm{C}_{3} \mathrm{H}_{6}$ $(+\mathrm{M})$. The latter reaction acts to decrease reactivity because it consumes hydrogen atoms in competition with the chain branching reaction $\dot{\mathrm{H}}+\mathrm{O}_{2} \leftrightarrow \ddot{\mathrm{O}}+\dot{\mathrm{O}} \mathrm{H}$.

In addition to the fuel in air flame speed measurements, the effects of various dilution ratios $\left(\mathrm{D}=\mathrm{O}_{2} /\left(\mathrm{O}_{2}+\mathrm{N}_{2}\right)\right.$ ) were also studied. The dilution ratios were: $0.18,0.19,0.20,0.209$ (air). Even minor modification of the dilution ratio leads to significant change in the laminar burning velocity as shown in Fig. 20(a). The effect of altering the composition of "air" by $0.5 \%$ from $21 \% \mathrm{O}_{2}$ and $79 \% \mathrm{~N}_{2}$ is shown in Fig. 20(b). There is approximately $5 \mathrm{~cm} / \mathrm{s}$ difference in the laminar flame speed at approximately $\phi=1.1$ for a fuel in air mixture containing $21.5 \% \mathrm{O}_{2}$ and $78.5 \% \mathrm{~N}_{2}$ and a mixture with $20.5 \% \mathrm{O}_{2}$ and $79.5 \% \mathrm{~N}_{2}$. Therefore, relatively small changes in mixture composition can have a significant effect on the laminar flame speed. This high sensitivity is a cumulative result of simultaneous increase (at a fixed equivalence ratio) of the fuel and oxidizer concentrations in expense of the inert concentration decrease, which in turn leads to an increased flame temperature and significant acceleration of the highly sensitive chain-branching reaction of $\dot{\mathrm{H}}+\mathrm{O}_{2}$ as seen in Fig. 19 (b).

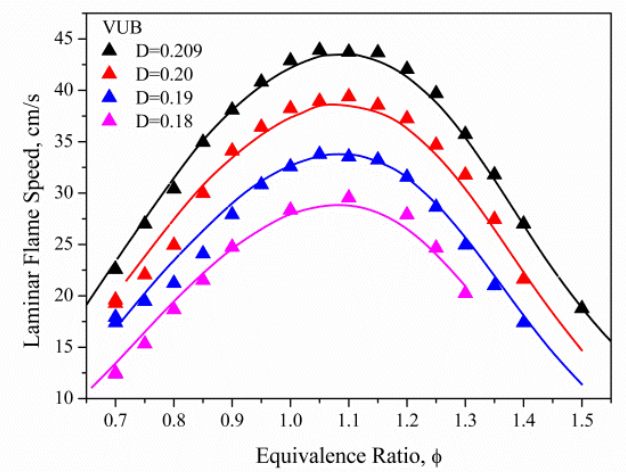

(a) Effect of altering dilution levels $\mathrm{D}=$ $\mathrm{O}_{2} /\left(\mathrm{O}_{2}+\mathrm{N}_{2}\right)$.

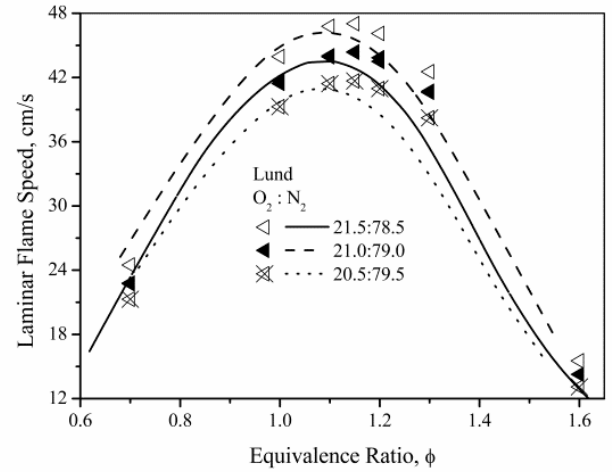

(b) Effect of altering "air" composition by \pm $0.5 \%$

Figure 20: Effect of altering the dilution levels on propene laminar flame speeds at $p=1$ atm. Symbols: experimental data, lines: current mechanism.

Figure 21 shows the mechanism performance against mass burning rate data for highpressure fuel-lean and fuel-rich flames obtained in the Princeton University facility. The experimental data shows a small effect of equivalence ratio on the mass burning rate, the fuellean data are approximately $15 \%$ faster than the fuel-rich data. The present mechanism can accurately predict the mass burning rate for the fuel-lean experiments; however, it underpredicts the mass burning rate for the fuel-rich data by approximately $50 \%$. The underprediction of the mass burning rate under fuel-rich conditions is consistent with the underprediction of the PU flame speed at 1 atm for fuel-rich mixtures as shown in Fig. 19(a). Thus the mismatch of the model predictions and experimental data cannot be attributed to the pressure effects in the experiments. In fact, the experimental uncertainty due to extrapolation and radiation becomes smaller at high pressure because of the reduced Markstein length (flame thickness) and increased heat release. Similar under-prediction of high pressure flame speed was also observed in rich dimethyl ether flames [44]. Sensitivity analysis showed that the model deficiency for high pressure rich flames is likely due to the large uncertainties in $\mathrm{HO}_{2}$-related reactions and the termination reactions $\dot{\mathrm{H}}+\dot{\mathrm{O}} \mathrm{H}(+\mathrm{M})=\mathrm{H}_{2} \mathrm{O}(+\mathrm{M})$ and $\dot{\mathrm{C}} \mathrm{H}_{3}+\dot{\mathrm{H}}$ $(+\mathrm{M})=\mathrm{CH}_{4}(+\mathrm{M})$ [44]. For rich propene flames, most probably the chemistry model should be further extended towards heavier hydrocarbons including aromatics. 


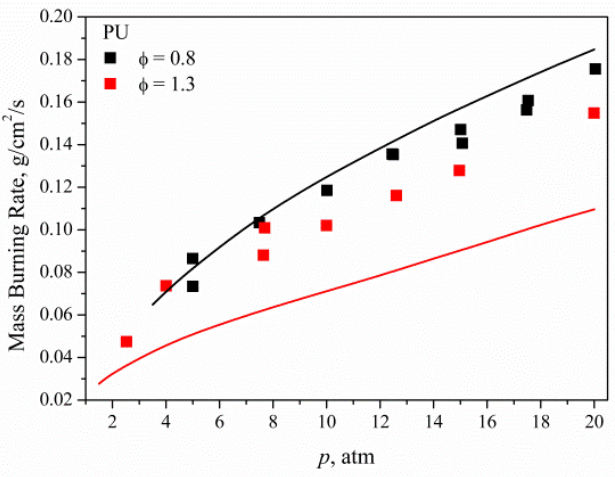

(a) High pressure mass burning rate $\phi=$ 0.8 and $1.3 \mathrm{p}=2.5-20 \mathrm{~atm}, \mathrm{~T}=298 \mathrm{~K}$

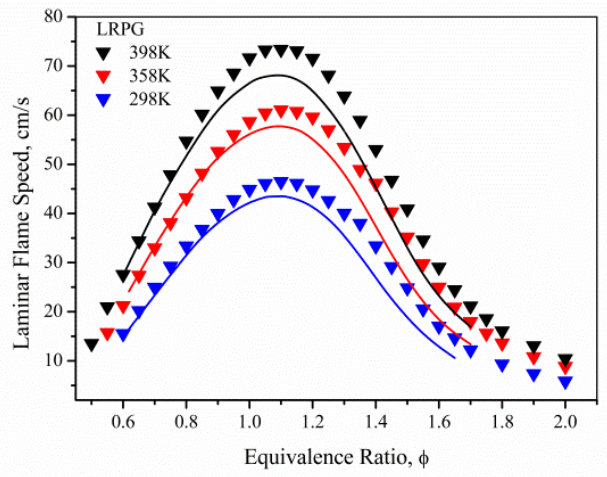

(b) High temperature laminar flame speeds $p=1 \mathrm{~atm}, T=298-398 \mathrm{~K}$.

Figure 21: Mass burning rates and laminar flame speeds for propene at elevated pressures and temperatures. Symbols: experimental data, lines: current mechanism.

\section{Conclusions}

New ignition delay time measurements were carried out in shock tubes and rapid compression machines at higher pressures and lower temperatures than previously published in the literature. The results presented in this study greatly expand the ignition delay time database available for mechanism validation for propene oxidation. Further, this is the first study of its kind to cross-validate ignition delay time measurements among six different shock tube and two different RCM facilities. Particularly for shock tubes, there is good agreement among measurements, which suggests that experimental shock tube IDTs can be wellreproduced even considering experimental method- and facility-specific variations. The current IDT measurements did not show any evidence of NTC-like behavior under the conditions studied.

New laminar flame speed measurements were obtained over a range of equivalence ratios, dilutions, and pressures from three different facilities using different methods. Measurements presented in this study considerably extend the pressure range of the propene laminar burning rate database up to 20 atm. There is good agreement among the facilities for fuel-lean mixtures; however, there are notable discrepancies under-fuel rich conditions, highlighting the need for further refinement of laminar flame speed experimental methods and a subsequent reduction in the lab-to-lab measurement uncertainties.

A new chemical kinetic mechanism has been validated against the new ignition data and is able to reproduce experimental measurements across a range of temperatures, pressures, and mixtures. Reactions shown to be sensitive in the prediction of propene ignition delay time include reactions between propene and molecular oxygen and propene and hydroxyl radicals. Allyl radical chemistry highlighted as being important includes the reactions of allyl and hydroperoxyl radicals and allyl and methyl radicals. The reactions between molecular oxygen and 1- and 2-propenyl radicals were also highlighted as sensitive. In flames propene reactions highlighted as important include propene decomposition, hydrogen atom abstraction by radicals such as hydroxyl radical and atomic hydrogen.

The performance of the current chemical kinetic mechanism is far improved over the performance of AramcoMech 1.3. It is important to note that AramcoMech 1.3 was validated against experimental data for $\mathrm{C}_{0}-\mathrm{C}_{2}$ species only. This study highlights the importance of only using a chemical kinetic mechanism within the confines of its validation limits. 


\section{Acknowledgements}

The Rensselaer group was supported by the U.S. Air Force Office of Scientific Research (Grant No. FA9550-11-1-0261) with Dr. Chiping Li as technical monitor.

Work at the University of Connecticut and at Princeton University was supported as part of the Combustion Energy Frontier Research Center, an Energy Frontier Research Center funded by the U.S. Department of Energy, Office of Science, Office of Basic Energy Science, under Award Number DE-SC0001198.

The work at Stanford University was supported by the Air Force Office of Scientific Research under the AFRL Integrated Product Team, with Dr. Chiping Li as contract monitor. 


\section{References}

[1]S.M. Burke, W.K. Metcalfe, O. Herbinet, F. Battin-Leclerc, F.M. Haas, J. Santner, F.L. Dryer, H.J. Curran, Combust. Flame (2014) accepted.

[2]A. Burcat, K. Radhakrishnan, Combust. Flame 60 (1985) 157-169.

[3]Y. Hidaka, T. Nakamura, H. Tanaka, A. Jinno, H. Kawano, T. Higashihara, Int. J.

Chem. Kinet. 24 (1992) 761-780.

[4]Z. Qin, H. Yang, W. C. Gardiner, Combust. Flame 124 (2001) 246-254.

[5]S.G. Davis, C.K. Law, H. Wang, Combust. Flame 119 (1999) 375-399.

[6]G. Jomaas, X.L. Zheng, D.L. Zhu, C.K. Law, Proc. Combust. Inst. 30 (2005) 193-200.

[7]K. Saeed, R. Stone, J. Energy Inst. 80 (2007) 73-82.

[8]H. Nakamura, D. Darcy, M. Mehl, C.J. Tobin, W.K. Metcalfe, W.J. Pitz, C.K.

Westbrook, H.J. Curran, Combust. Flame 161 (2014) 49-64.

[9] C. Morley, Gaseq, version 0.76, 2004.

[10]E. Goos, A. Burcat, B. Ruscic, Ideal gas thermochemical database with updates from active thermochemical tables,

ftp://ftp.technion.ac.il/pub/supported/aetdd/thermodynamics, 2012.

[11] H.-P. S. Shen, J. Vanderover, M.A. Oehlschlaeger, Proc. Combust. Inst. 32 (2009)

$165-172$.

[12]E.L. Petersen, A Shock Tube and Diagnostics for Chemistry Measurements at

Elevated Pressures with Application to Methane Ignition., Ph.D. thesis, Department of

Mechanical Engineering, Stanford University, 1998.

[13] C.J. Aul, W.K. Metcalfe, S.M. Burke, H.J. Curran, E.L. Petersen, Combust. Flame

160 (2013) 1153-1167.

[14]H-P.S. Shen, M.A. Oehlschlaeger, Combust. Flame 156 (2009) 1053-1062.

[15] A. Gaydon, I. Hurle, The shock tube in high-temperature chemical physics, Chapman and Hall, 1963.

[16]Z.K. Hong, G.A. Pang, S.S. Vasu, D.F. Davidson, R.K. Hanson, Shock Waves 19

(2009) 113-123.

[17]E.L. Petersen, Combust. Sci. Technol. 181 (2009) 1123-1144.

[18]D. Darcy, H. Nakamura, C.J. Tobin, M. Mehl, W.K. Metcalfe, W.J. Pitz, C.K.

Westbrook, H.J. Curran, Combust. Flame 161 (2014) 65-74.

[19] W. Affleck, A. Thomas, Proc. Inst. Mech. Eng 183 (1968) 365-387.

[20]G. Mittal, C.-J. Sung, Combust. Sci. Technol. 179 (2007) 497-530.

[21] J.M. Hall, E.L. Petersen, Int. J. Chem. Kinet. 38 (2006) 714-724.

[22] T. Kathrotia, M. Fikri, M. Bozkurt, M. Hartmann, U. Riedel, C. Schulz, Combust.

Flame 157 (2010) 1261-1273.

[23] G. Mittal, C.J. Sung, M. Fairweather, A.S. Tomlin, J.F. Griffiths, K.J. Hughes, Proc.

Combust. Inst. 31 (2007) 419-427.

[24] X. Qin, Y. Ju, Proc. Combust. Inst. 30 (2005) 233-240.

[25] M.P. Burke, Z. Chen, Y. Ju, F.L. Dryer, Combust. Flame 156 (2009) 771-779.

[26] Z. Chen, Combust. Flame 158 (2011) 291-300.

[27] J. Santner, F.M. Haas, F.L. Dryer, Combust. Flame 161 (2014) 147-153

[28] A.A. Konnov, I.V. Dyakov, J. De Ruyck, Combust. Sci. Technol. 169 (2001) 127153.

[29]I. Dyakov, A.A. Konnov, J.D. Ruyck, K.J. Bosschaart, E.C.M. Brock, L.P.H. De

Goey, Combust. Sci. Technol. 172 (2001) 81-96.

[30] K. Bosschaart, L. de Goey, Combust. Flame 136 (2003) 170-180.

[31] M.C. Krejci, O. Mathieu, A.J. Vissotski, S. Ravi, T.G. Sikes, E.L. Petersen, A.

Kérmonès, W.K. Metcalfe, H.J. Curran, J. Eng. Gas Turb. Power 135 (2) (2103) 021503- 
1-021503-9.

[32]R.J. Moffat, Exp. Thermal Fluid Sci. (1) (1988) 3-17.

[33]P. Dirrenberger, H. Le Gall, R. Bounaceur, O. Herbinet, P.A. Glaude, S. Konnov, F. Battin-Leclerc. Energy Fuels 25 (2011) 3875-3884.

[34]P. Dirrenberger, P.A. Glaude, R. Bounaceur, H. Le Gall, A. Pires da Cruz, A.A.

Konnov, F. Battin-Leclerc. Fuel 115 (2014) 162-169.

[35] M.E. Bardin, E. V. Ivanov, E.J.K. Nilsson, V. A. Vinokurov, A. A. Konnov. Energy Fuels 27(9) (2013) 5513-5517.

[36]R.J. Kee, J.F. Grcar, M.D. Smooke, J.A. Miller, A Fortran Program for Modeling Steady Laminar One-Dimensional Premixed Flames.

[37]R. Kee, F. Rupley, J. Miller, M. Coltrin, J. Grcar, E. Meeks, H. Moffat, A. Lutz, G. Dixon-Lewis, M. Smooke, J. Warnatz, G. Evans, R. Larson, R. Mitchell, L. Petzold, W. Reynolds, M. Caracotsios, W. Stewart, P. Glarborg, C. Wang, C. McLellan, O. Adigun, W. Houf, C. Chou, S. Miller, P. Ho, P. Young, D. Young, D. Hodgson, M. Petrova, K. Puduppakkam, CHEMKIN-PRO Release 15101, 2010, Reaction Design: San Diego (2007).

[38] W.K. Metcalfe, S.M. Burke, S.S. Ahmed, H.J. Curran, Int. J. Chem. Kinet. 45 (2013) 638-675.

[39] S.S. Vasu, Z. Hong, D.F. Davidson, R.K. Hanson, D.M. Golden, J. Phys. Chem. A 114 (2010) 11529-11537.

[40] J. Zádor, A.W. Jasper, and J.A. Miller, Phys. Chem. Chem. Phys. 11 (2009) 1104011053.

[41] C.F. Goldsmith, S. J. Klippenstein, W. H. Green, Proc. Combust. Inst. 33 (2011) 273-282.

[42]F.J. Wu, W.K. Liang, Z. Chen, Y. Ju, C.K. Law, C.K. "Uncertainty in Stretch Extrapolation of Laminar Flame Speed from Expanding Spherical Flames" Proc Combust. Inst. 35 (2014) in press.

[43] L. Sileghem, V.A. Alekseev, J. Vancoillie, E.J.K. Nilsson, S. Verhelst, A.A.

Konnov, Fuel 115 (2014) 32-40.

[44]D. Liu, J. Santner, C. Togbé, D. Felsmann, J. Koppmann, A. Lackner, A., X. Yang, X. Shen, Y. Ju, K. Kohse-Höinghaus, Combust. Flame 160(12) (2013) 2654-2668. 